\title{
Hydrometallurgical Recovery of Rare Earth Elements from NdFeB Permanent Magnet Scrap: A Review
}

\author{
Yuanbo Zhang ${ }^{1, *}$, Foquan Gu ${ }^{1, * \mathbb{D}}, \mathrm{Zijian} \mathrm{Su}^{1}{ }^{1}$, Shuo Liu ${ }^{1}$, Corby Anderson ${ }^{2}$ and Tao Jiang ${ }^{1}$ \\ 1 School of Minerals Processing and Bioengineering, Central South University, Changsha 410083, China; \\ szjcsu@163.com (Z.S.); lsus91@163.com (S.L.); jiangtao@csu.edu.cn (T.J.) \\ 2 Department of Metallurgical and Materials Engineering, Colorado School of Mines, Golden, CO 80401, USA; \\ cganders@mines.edu \\ * Correspondence: sintering@csu.edu.cn (Y.Z.); gufoquan@csu.edu.cn (F.G.)
}

Received: 30 May 2020; Accepted: 15 June 2020; Published: 24 June 2020

\begin{abstract}
NdFeB permanent magnet scrap is regarded as an important secondary resource which contains rare earth elements (REEs) such as $\mathrm{Nd}, \mathrm{Pr}$ and Dy. Recovering these valuable REEs from the $\mathrm{NdFeB}$ permanent magnet scrap not only increases economic potential, but it also helps to reduce problems relating to disposal and the environment. Hydrometallurgical routes are considered to be the primary choice for recovering the REEs because of higher REEs recovery and its application to all types of magnet compositions. In this paper, the authors firstly reviewed the chemical and physical properties of $\mathrm{NdFeB}$ permanent magnet scrap, and then carried out an in-depth discussion on a variety of hydrometallurgical processes for recovering REEs from the NdFeB permanent magnet scrap. The methods mainly included selective leaching or complete leaching processes followed by precipitation, solvent extraction or ionic liquids extraction processes. Particular attention is devoted to the specific technical challenge that emerges in the hydrometallurgical recovery of REEs from NdFeB permanent magnet scrap and to the corresponding potential measures for improving REEs recovery by promoting the processing efficiency. This summarized review will be useful for researchers who are developing processes for recovering REEs from NdFeB permanent magnet scrap.
\end{abstract}

Keywords: rare earth elements; $\mathrm{NdFeB}$ permanent magnet; hydrometallurgical; recovery

\section{Introduction}

$\mathrm{NdFeB}$ magnets are considered as the strongest permanent magnets with the highest energy product $\mathrm{BH}_{\max }\left(200-440 \mathrm{~kJ} / \mathrm{m}^{3}\right)$ of all permanent magnets [1]. They are widely used in wind turbines, hybrid electric vehicles, hydro-electric turbine generators, etc. [2]. Figure 1 shows the proportion of the different applications around the global NdFeB market.

Depending on the application field of $\mathrm{NdFeB}$ magnets, they have different life cycles and weight. The life cycles of $\mathrm{NdFeB}$ magnets range from 2-3 years for consumer electronics to 20-30 years in wind turbines. Meanwhile, the weight of $\mathrm{NdFeB}$ magnets ranges from less than $1 \mathrm{~g}$ for small electronics to $1-2 \mathrm{t}$ for wind turbines [4]. The phase of NdFeB magnets based on ( $\mathrm{Nd}, \mathrm{Pr}, \mathrm{Dy})-\mathrm{Fe}-\mathrm{B}$ and other trace elements, with REEs contents of 27-32 wt.\%, Fe content of 67-73 wt.\%, B content of about 1 wt.\% [5,6], and other minor metals, are determined by the applications of NdFeB magnets. Obviously, recovering REEs from NdFeB magnet scrap has good economic benefits.

Recyclable materials of $\mathrm{NdFeB}$ magnets scrap mainly include: (1) swarf originating from magnet manufacturing; (2) large magnets in wind turbines; (3) small magnets in End-of-Life consumer products. About 20-30 wt.\% scrap is generated during the NdFeB magnets cutting and grinding processes, and $95 \%$ of those scraps can be recycled $[7,8]$. The NdFeB magnets used in wind turbines, hybrid vehicles and electric vehicles are easy to directly recycle or re-use [9]. However, it remains a social and 
technological challenge to collect and recover the magnets from the End-of-Life of small consumer electronics. In view of the potential economic and environmental benefits of utilizing the $\mathrm{NdFeB}$ magnet scrap, it is significant to develop appropriate methods for treating the NdFeB magnet scrap. At present, recycling of $\mathrm{NdFeB}$ magnet scrap mainly focus on the recovery of REEs. The disclosed methods include direct re-use in current form/shape [10-15], reprocessing of alloys to magnets after hydrogen decrepitation [12,14-18], pyrometallurgical methods [19-28], gas-phase extraction [29,30], and hydrometallurgical methods [31-37]. In Table 1, an overview of different methods for NdFeB magnet scrap recycling is given.

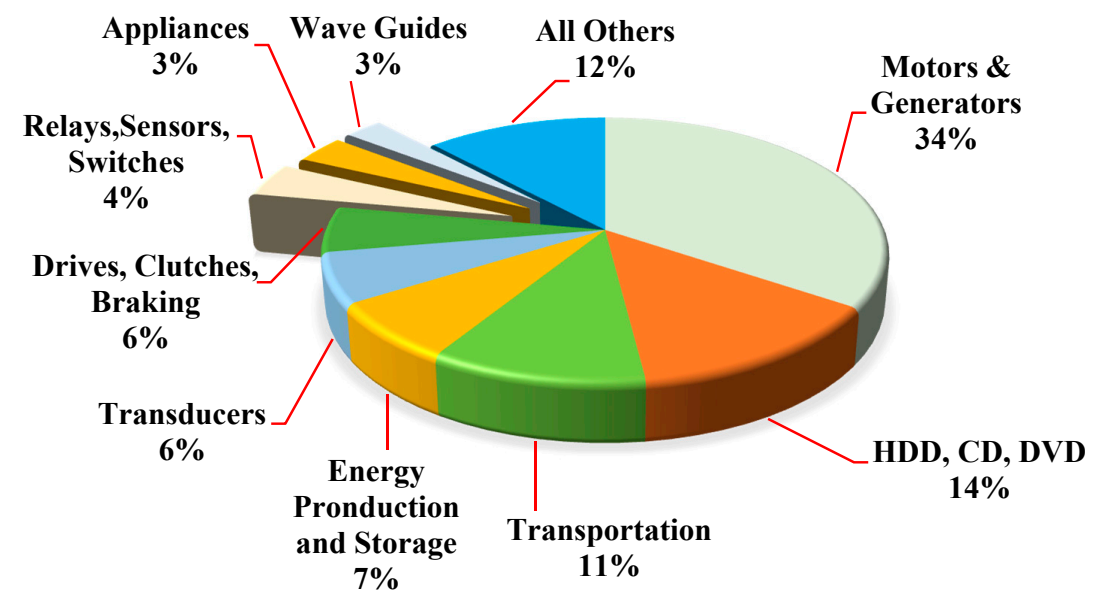

Figure 1. The proportion of different applications around the global NdFeB magnet market, data from [3].

Table 1. Overview of the advantages and disadvantages of different methods for NdFeB magnet scrap recycling, Reproduced with permission from [38]; published by Elsevier, 2013.

\begin{tabular}{|c|c|c|}
\hline Method & Advantages & Disadvantages \\
\hline $\begin{array}{l}\text { Direct re-use in } \\
\text { current form/shape }\end{array}$ & $\begin{array}{l}\text { Most economical way of recycling } \\
\text { (low energy input, no consumption } \\
\text { of chemicals) } \\
\text { - No waste generated }\end{array}$ & $\begin{array}{l}\text { - Only for large, easily accessible } \\
\text { magnets (wind turbines, large } \\
\text { electric motors and generators in } \\
\text { hybrid and electric vehicles) } \\
\text { - } \quad \text { Not available in large quantities in } \\
\text { scrap today }\end{array}$ \\
\hline $\begin{array}{l}\text { Reprocessing of } \\
\text { alloys to magnets } \\
\text { after hydrogen } \\
\text { decrepitation }\end{array}$ & $\begin{array}{l}\text { - Less energy input required than for } \\
\text { hydrometallurgical and } \\
\text { pyrometallurgical routes } \\
\text { - No waste generated } \\
\text { - Especially suited for hard disk } \\
\text { drives (little compositional change } \\
\text { over the years) }\end{array}$ & $\begin{array}{l}\text { - Not applicable to mixed scrap feed, } \\
\text { which contains magnets with large } \\
\text { compositional variations } \\
\text { - Not applicable to } \\
\text { oxidized magnets }\end{array}$ \\
\hline $\begin{array}{l}\text { Pyrometallurgical } \\
\text { methods }\end{array}$ & $\begin{array}{l}\text { - } \quad \text { Generally applicable to all types of } \\
\text { magnet compositions } \\
\text { - } \quad \text { No generation of waste water } \\
\text { hydrometallurgical methods } \\
\text { - } \quad \text { Direct melting allows master alloys } \\
\text { to be obtained } \\
\text { - Liquid metal extraction allows REEs } \\
\text { to be obtained in metallic state }\end{array}$ & $\begin{array}{l}\text { - } \quad \text { Larger energy input required } \\
\text { Direct smelting and liquid metal } \\
\text { extraction cannot be applied to } \\
\text { oxidized magnets } \\
\text { - } \quad \begin{array}{l}\text { Electroslag refining and the glass } \\
\text { slag method generate large } \\
\text { amounts of solid waste }\end{array}\end{array}$ \\
\hline
\end{tabular}


Table 1. Cont.

\begin{tabular}{|c|c|c|}
\hline Method & Advantages & Disadvantages \\
\hline Gas-phase extraction & $\begin{array}{l}\text { - Generally applicable to all types of } \\
\text { magnet compositions } \\
\text { Applicable to non-oxidized and } \\
\text { oxidized alloys } \\
\text { - } \quad \text { No generation of waste water }\end{array}$ & $\begin{array}{l}\text { - Consumption of large amounts of } \\
\text { chlorine gas } \\
\text { - Aluminum chloride is } \\
\text { very corrosive }\end{array}$ \\
\hline $\begin{array}{l}\text { Hydrometallurgical } \\
\text { methods }\end{array}$ & $\begin{array}{l}\text { Generally applicable to all types of } \\
\text { magnet compositions } \\
\text { Applicable to non-oxidized and } \\
\text { oxidized alloys } \\
\text { - Same processing steps as those for } \\
\text { extraction of rare earths from } \\
\text { primary ores }\end{array}$ & $\begin{array}{l}\text { - Many process steps required } \\
\text { before obtaining new magnets } \\
\text { - } \quad \text { Consumption of large amounts } \\
\text { of chemicals } \\
\text { - Generation of large amounts of } \\
\text { waste water }\end{array}$ \\
\hline
\end{tabular}

Recycling of NdFeB magnet scrap has been researched broadly and various methods have been carried out. Among these methods, the hydrometallurgical methods seem to be the most prominent for recovering REEs from $\mathrm{NdFeB}$ magnet scrap because hydrometallurgical methods can be used to treat all types of magnets. More importantly, hydrometallurgical methods can be well connected with the existing REEs production industry. The purpose of the present paper is to provide an overview of REEs recovering from NdFeB magnet scrap by hydrometallurgical processes. The recycling potential of $\mathrm{NdFeB}$ permanent magnet scraps is firstly clarified, and then the chemical and physical characteristics of $\mathrm{NdFeB}$ permanent magnet scrap are provided. Lastly, hydrometallurgical methods for recovering REEs from $\mathrm{NdFeB}$ permanent magnet scrap are reviewed. This paper aims to offer a useful guideline for sustainable recovering REEs from $\mathrm{NdFeB}$ permanent magnet scrap.

\section{Recycling Potential of NdFeB Permanent Magnet Scrap}

According to the United States Geological Survey (USGS), the global annual consumption of rare earth oxides is about 120,000 $\mathrm{t}$ [39]. The market share of global consumption of rare earth oxides is shown in Figure 2; approximately 26,400 t of rare earth oxides are used in the permanent magnet market, accounting for a large proportion among all rare earth oxides consumption.

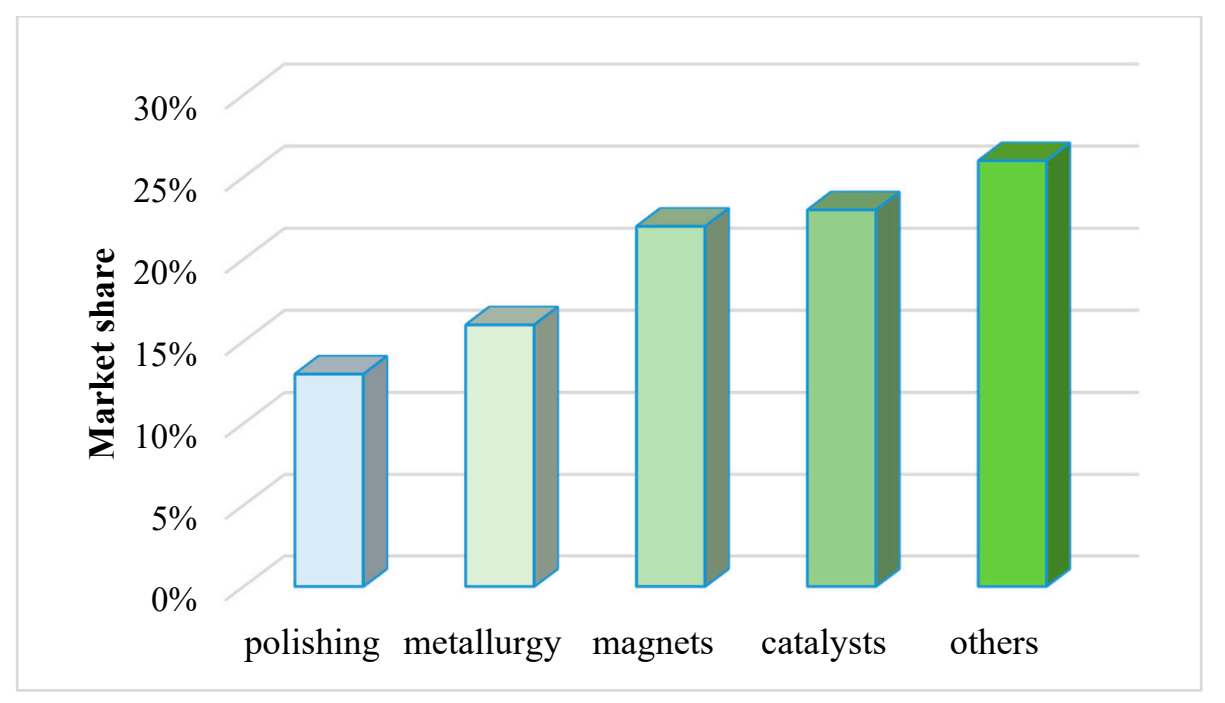

Figure 2. Market share of global consumption of rare earth oxides (based on data from the United States Geological Survey (USGS) [39]). 
Alonso et al. [40] estimated the growths of market share of global REEs consumption according to the applications. As seen from Figure 3, the fraction of REEs demand in the magnets increased continuously until 2035. The magnets will become the most in-demand materials of REEs, and the fraction of REEs demand will be close to $50 \%$, because of the rapidly developing technologies for clean energy and transportation (e.g., electric vehicles and wind turbines).

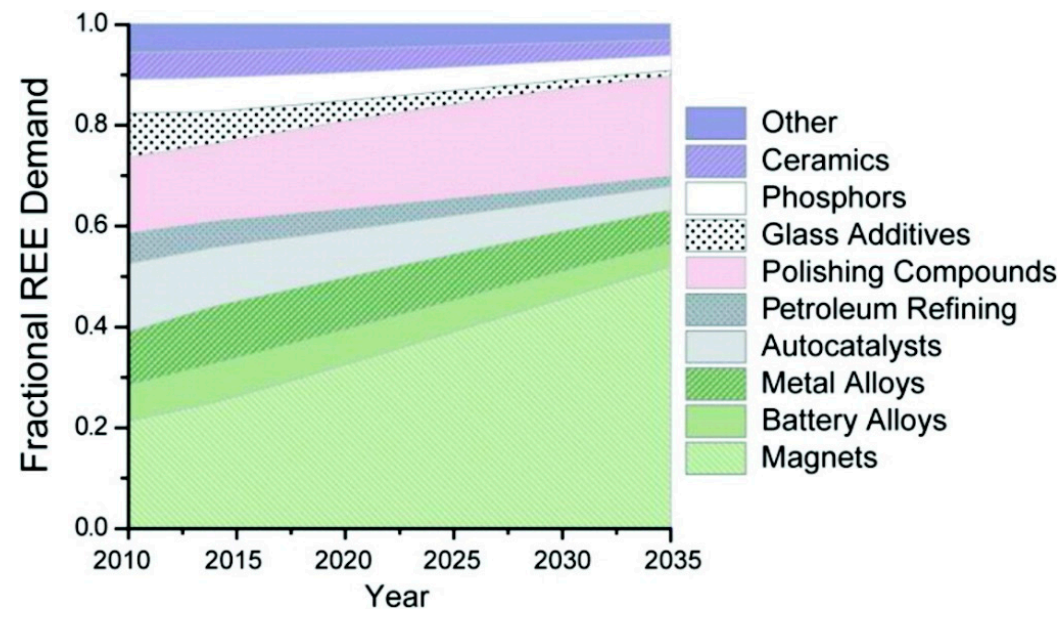

Figure 3. Predicted growths of market share of global rare earth elements (REEs) consumption [40]; published by American Chemical Society, 2012.

Schulze et al. [41] calculated the NdFeB demand for magnets used in different application groups and net availability of secondary NdFeB supply from End-of-Life (EOL) magnets from 2020 to 2030 based on low and high $\mathrm{NdFeB}$ demand scenario. As shown in Figure 4, the demand of NdFeB and the net availability of secondary $\mathrm{NdFeB}$ supply from EOL magnets both increase gradually. The demand of NdFeBis about $240 \mathrm{kt}$ and $633 \mathrm{kt}$ in 2030 for the low and high NdFeB demand scenario, respectively. Meanwhile, the net availability of secondary NdFeB supply from EOL magnets is about $27 \mathrm{kt}$ and $54 \mathrm{kt}$ in 2030 for the low and high NdFeB demand scenario, respectively. Obviously, the recovery of NdFeB magnets possesses huge potential value.

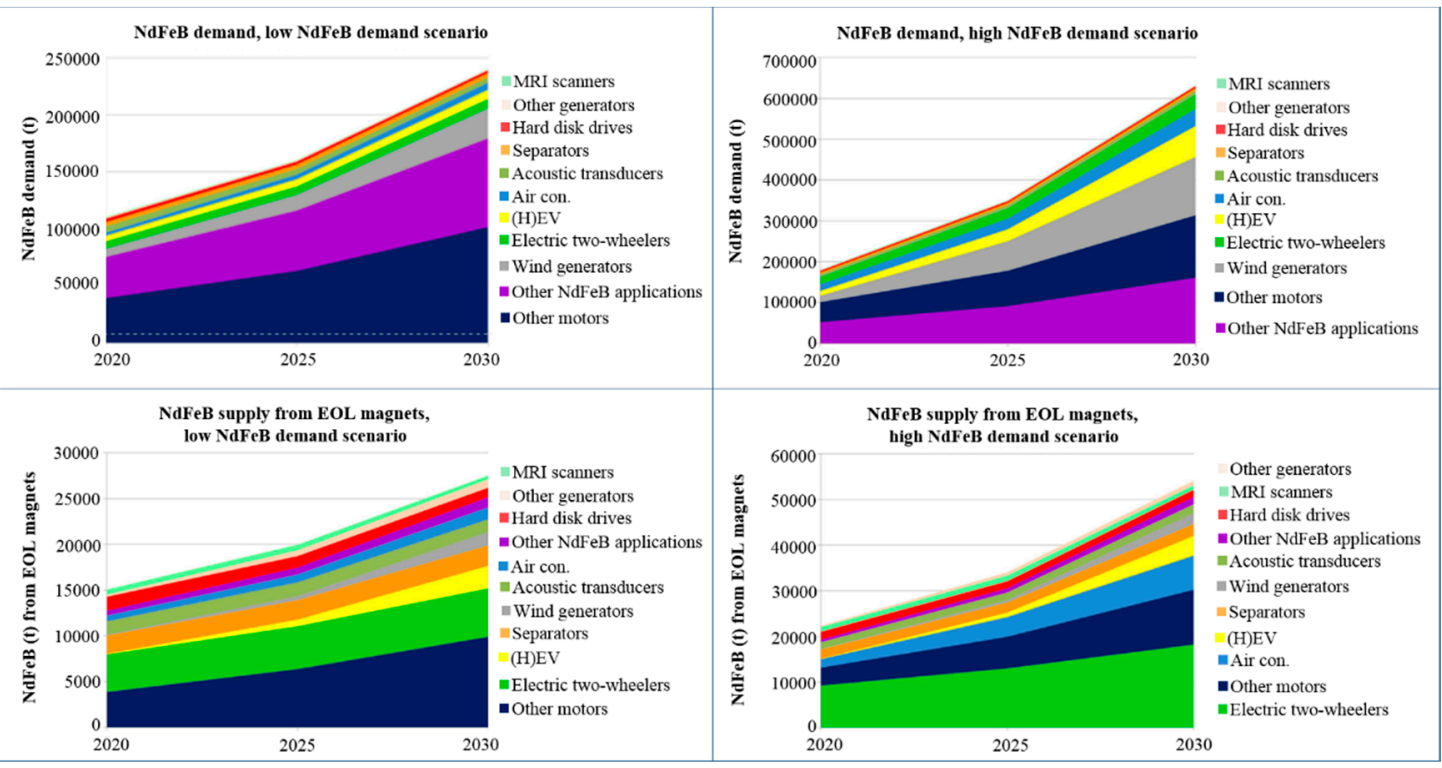

Figure 4. NdFeB demand and net supply from End-of-Life (EOL) magnets (losses during collection and disassembly have been subtracted) [41]; published by Elsevier, 2016. 
The historical data (1983-2007) of NdFeB permanent magnets from China, Japan, the United States and Europe were used to estimate the global stock of REEs in NdFeB permanent magnets. The results showed that about $62.6 \mathrm{kt} \mathrm{Nd}, 15.7 \mathrm{kt} \mathrm{Pr}, 15.7 \mathrm{kt}$ Dy and $3.1 \mathrm{kt} \mathrm{Tb}$ were stocked in NdFeB permanent magnets from 1983 to 2007 . If these stocks are effectively recovered, they can serve as a valuable supplement to the geological stocks because they are about four times of the 2007 annual extraction of the individual elements [42]. Guyonnet et al. [43] presented an analysis of flows and stocks of some REEs along the value chain in Europe. The analysis indicated that in 2010, about $580 \mathrm{t} \mathrm{Nd}$ and $70 \mathrm{t} \mathrm{Dy}$ were wasted. The Sankey diagrams illustrate the serious imbalance of flows of REEs in NdFeB magnets along the value chain, and the Europe mainly depends on the import of finished products. They also indicated that the recirculation flow of $\mathrm{Nd}$ in $\mathrm{NdFeB}$ magnets is expected to be 170-230 $\mathrm{t}$ in 2020 .

Schulze and Buchert [44] quantitatively analyzed the global recycling potential of EOL magnets from different application groups and industrial waste by dynamic material flow analysis. The modelled scenario shows that $18-22 \%$ of the global $\mathrm{Nd}$ and Pr and $20-23 \%$ of Dy and $\mathrm{Tb}$ used in NdFeB magnet production can be provided by EOL magnets and industrial scrap in 2020, 2025 and 2030. In another study [45], the authors estimated annual waste flows of $\mathrm{Nd}$ and $\mathrm{Dy}$ from three common permanent magnets. The results indicate that for some time to come, compared to the rapidly growing global REEs demand, the waste stream generated by permanent magnets will remain small, and the global recycling potential for the next few decades is also limited. Due to the small amount of waste, recycling at an economically advantageous scale is impossible. However, in the long term, waste stream generated by permanent magnets will increase dramatically and meet a large portion of the total demand for REEs. Therefore, those authors highlight that the NdFeB magnet is one of the most important secondary resources for the recovery of $\mathrm{Nd}$ and $\mathrm{Dy}$. It is also suggested that decision makers should develop recycling technology through pilot projects, which should take about five to ten years to establish recycling practices [41].

There is no denying that recycling is a key technology for metal recycling from various sources. However, at present, recycling of REEs is within $1 \%$, but the current situation demands that we improve the recycling of REEs from REEs-bearing wastes [38]. The NdFeB permanent magnet is an important REEs demanded material, and the NdFeB permanent magnet scrap has huge potential for REEs recovery.

\section{Chemical and Physical Characteristics of NdFeB Permanent Magnet Scrap}

The chemical and physical properties of $\mathrm{NdFeB}$ permanent magnet scrap are the starting point for choosing a suitable recycling process. These characteristics mainly include chemical composition, phase composition, and microstructural morphology.

\subsection{Chemical Composition}

Table 2 lists typical chemical compositions of NdFeB permanent magnet scraps. In fact, according to the compositions of REEs, $\mathrm{NdFeB}$ permanent magnet scraps can be classified into three categories, namely low REEs scraps (the contents of REEs $<20 \mathrm{wt} . \%$ ), medium REEs scraps (the contents of REEs about 20-30 wt.\%), and high REEs scraps (the contents of REEs $>30 \mathrm{wt} . \%$ ). All types of NdFeB permanent magnet scraps contain $\mathrm{Nd}$, sometimes, $\mathrm{Tb}, \mathrm{Dy}$, and $\mathrm{Gd}$ are also added to replace some fractions of $\mathrm{Nd}$ to increase the operating temperature and intrinsic coercivity of $\mathrm{NdFeB}$ permanent magnet $[46,47]$. Pr, La, and Sm are generally added to replace $\mathrm{Nd}$ at a lower production cost [48]. The addition of $\mathrm{Co}$ can improve the Curie temperature of the magnet [49]. The addition of $\mathrm{Al}, \mathrm{Cu}, \mathrm{Nb}$, and $\mathrm{Ni}$ is proposed to replace some $\mathrm{Fe}$, to increase the coercivity of $\mathrm{NdFeB}$ permanent magnet [50]. 
Table 2. Typical chemical compositions of NdFeB magnet scrap (wt.\%).

\begin{tabular}{|c|c|c|c|c|c|c|c|c|c|c|c|c|c|c|c|}
\hline Typical & $\mathrm{Nd}$ & $\mathrm{Fe}$ & B & $\operatorname{Pr}$ & Dy & Co & $\mathrm{Sm}$ & La & $\mathrm{Nb}$ & $\mathrm{Gd}$ & $\mathrm{Tb}$ & $\mathrm{Cu}$ & Al & $\mathrm{Ni}$ & Refs. \\
\hline \multirow{2}{*}{$\begin{array}{l}\text { Low REE } \\
\text { sscraps }\end{array}$} & 10.70 & 79.20 & 5.75 & 2.68 & 0.43 & 0.79 & - & - & - & - & - & 0.11 & 0.19 & - & [16] \\
\hline & 14.00 & 78.00 & 6.00 & - & 0.60 & - & - & - & 0.40 & - & - & - & 0.70 & - & [19] \\
\hline \multirow{6}{*}{$\begin{array}{l}\text { Medium } \\
\text { REEs } \\
\text { scraps }\end{array}$} & 26.10 & 63.50 & 0.73 & 0.68 & 2.68 & 2.99 & - & - & - & 0.02 & - & - & 0.35 & - & [51] \\
\hline & 25.38 & 61.09 & 1.00 & 2.62 & 1.08 & 1.42 & - & - & - & - & - & - & 0.95 & 2.03 & [52] \\
\hline & 28.00 & 68.00 & 1.00 & - & 1.00 & - & - & - & - & - & - & - & & 1.00 & [53] \\
\hline & 23.70 & 66.10 & 0.91 & 0.12 & 2.42 & 3.34 & - & - & - & - & - & - & & 3.00 & [13] \\
\hline & 24.43 & 64.07 & 0.97 & - & - & 1.67 & - & - & 0.37 & - & - & 0.15 & 0.20 & - & [54] \\
\hline & 21.00 & 70.60 & 1.04 & - & 6.30 & 0.57 & - & - & - & - & - & 0.15 & - & - & [8] \\
\hline \multirow{6}{*}{$\begin{array}{l}\text { High } \\
\text { REEs } \\
\text { scraps }\end{array}$} & 19.40 & 66.30 & 0.96 & 6.43 & 5.21 & - & 0.77 & - & - & - & - & - & - & 0.87 & [31] \\
\hline & 30.73 & 61.60 & 0.96 & 4.39 & - & - & - & 1.58 & - & - & - & - & 0.83 & - & [25] \\
\hline & 18.80 & 63.90 & 1.02 & 5.98 & 5.93 & 0.42 & - & - & - & 1.51 & - & - & 1.04 & & [55] \\
\hline & 25.95 & 58.16 & 1.00 & 0.34 & 4.21 & 4.22 & - & - & - & - & - & - & 0.34 & 0.02 & [34] \\
\hline & 25.95 & 58.16 & 1.00 & 0.07 & 4.21 & 4.22 & - & - & 0.83 & - & - & - & 0.34 & 0.02 & [56] \\
\hline & 22.57 & 67.15 & 0.98 & 7.10 & 0.79 & 0.74 & - & - & - & - & 0.41 & - & - & - & [14] \\
\hline
\end{tabular}




\subsection{Phase Composition}

The main phase of the $\mathrm{NdFeB}$ magnet scrap is $\mathrm{Nd}_{2} \mathrm{Fe}_{14} \mathrm{~B}$ [54,57], which accounts for 96-98\%. Herbst et al. indicated the unit cell structure of $\mathrm{Nd}_{2} \mathrm{Fe}_{14} \mathrm{~B}$. The space group is $P 4_{2} / m n m$, and there are four $\mathrm{Nd}_{2} \mathrm{Fe}_{14} \mathrm{~B}$ units (68 atoms) per unit cell. All the $\mathrm{Nd}$ and $\mathrm{B}$ atoms, but only four of the $56 \mathrm{Fe}$ atoms, reside in the $\mathrm{z}=0$ and $\mathrm{z}=0.5$ planes. Between these, the other Fe atoms form puckered, yet fully connected, hexagonal nets [58]. Apart from $\mathrm{Nd}_{2} \mathrm{Fe}_{14} \mathrm{~B}, \mathrm{NdO}, \mathrm{Nd}_{2} \mathrm{O}_{3}$, and the minor $\mathrm{NdFe}_{4} \mathrm{~B}_{4} \mathrm{may}$ appear in the grain boundary $[51,55]$.

\subsection{Microstructural Morphology}

The coercivity of the $\mathrm{NdFeB}$ magnets is closely related to the interface microstructure between main phase $\left(\mathrm{Nd}_{2} \mathrm{Fe}_{14} \mathrm{~B}\right)$ and the grain boundary phase (Nd-rich) [59]. Figure 5 shows the SEM images of the NdFeB magnet. Grain sizes of the NdFeB magnet are very small (Figure 5 left), and small agglomerates of the Nd-rich phase are also observed. The field emission gun scanning electron microscope image (Figure 5 right) shows a uniform continuous coating of $\mathrm{Nd}_{2} \mathrm{Fe}_{14} \mathrm{~B}$ grains, where the thickness of the Nd-rich grain boundary phase is a few nanometers, separating the individual grains. Scanning electron microscopy-energy dispersive X-ray spectroscopy (SEM-EDS) analysis was carried out to identify the compositional variation in the NdFeB magnets, and the results are listed in Figure 6. The results indicate that the $\mathrm{Nd}$ is concentrated in the grain boundaries instead of within the grains, and the Fe is concentrated within the grains.
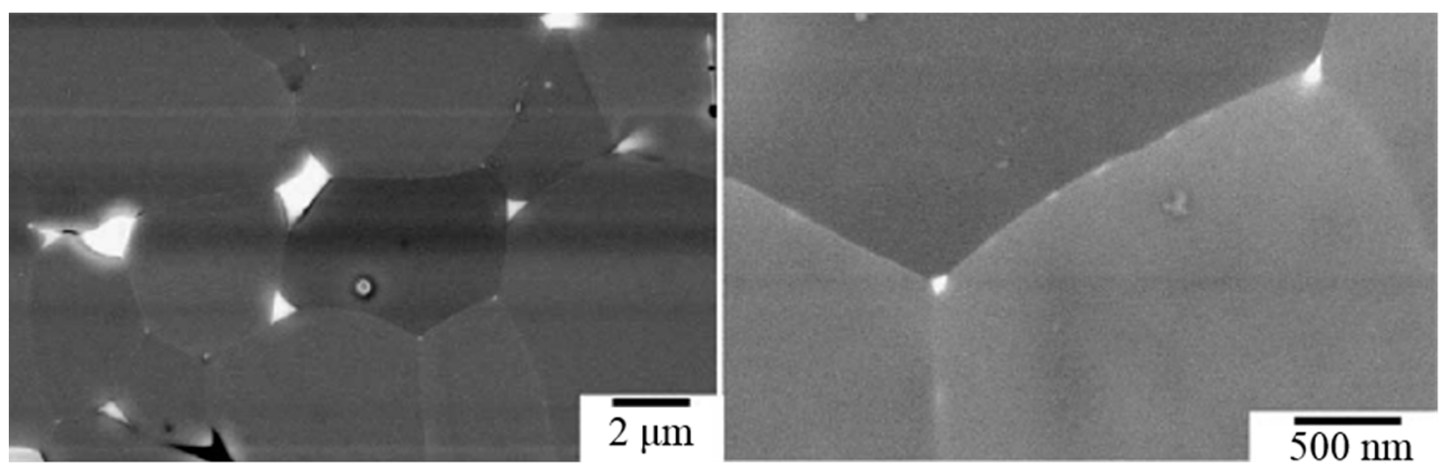

Figure 5. SEM images of NdFeB permanent magnets [59]; published by Elsevier, 2004.

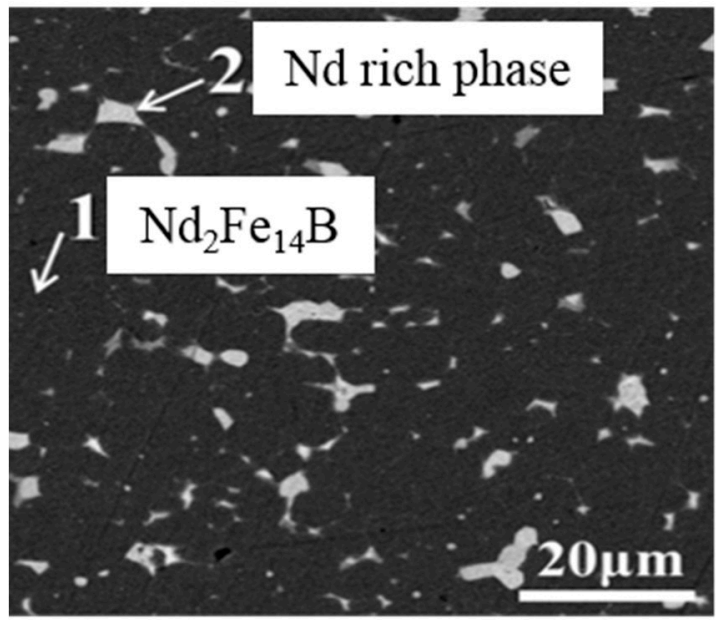

\begin{tabular}{|c|c|c|}
\hline \multicolumn{3}{|c|}{ EDS results } \\
\hline & Spot 1 & Spot 2 \\
\hline Nd & 87.9 & 26.1 \\
\hline Fe & 2 & 73.9 \\
\hline Dy & 5.4 & - \\
\hline O & 4.7 & - \\
\hline
\end{tabular}

Figure 6. SEM-EDS analysis of NdFeB permanent magnets [54]; published by Elsevier, 2014.

The distribution of $\mathrm{Nd}, \mathrm{Dy}, \mathrm{C}, \mathrm{Al}, \mathrm{Si}, \mathrm{Fe}, \mathrm{Ce}$, and Pr in the NdFeB magnet scrap was analyzed using energy dispersive $X$-ray spectroscopy (EDX) mapping. As shown in Figure 7, the Fe is most abundant in the matrix, while $\mathrm{Nd}$ and Pr are located in the grains and concentrated on the grain 
boundaries. Dy and Ce are nearly evenly distributed over the surface [60]. According to Önal et al., the area dominated by $\mathrm{Fe}$ indicates the $\mathrm{Nd}_{2} \mathrm{Fe}_{14} \mathrm{~B}$ phase and the area highlighted by $\mathrm{Nd}$ and $\mathrm{O}$ represent the grain boundary phase. An area with a high $B$ concentration represents the presence of $\mathrm{Nd}_{1} \mathrm{Fe}_{4} \mathrm{~B}_{4}$ phase. They also concluded that all target metals are distributed over the entire microstructure of the magnet and the structure needs to be completely destroyed to recover valuable metals from the $\mathrm{NdFeB}$ magnet [61].
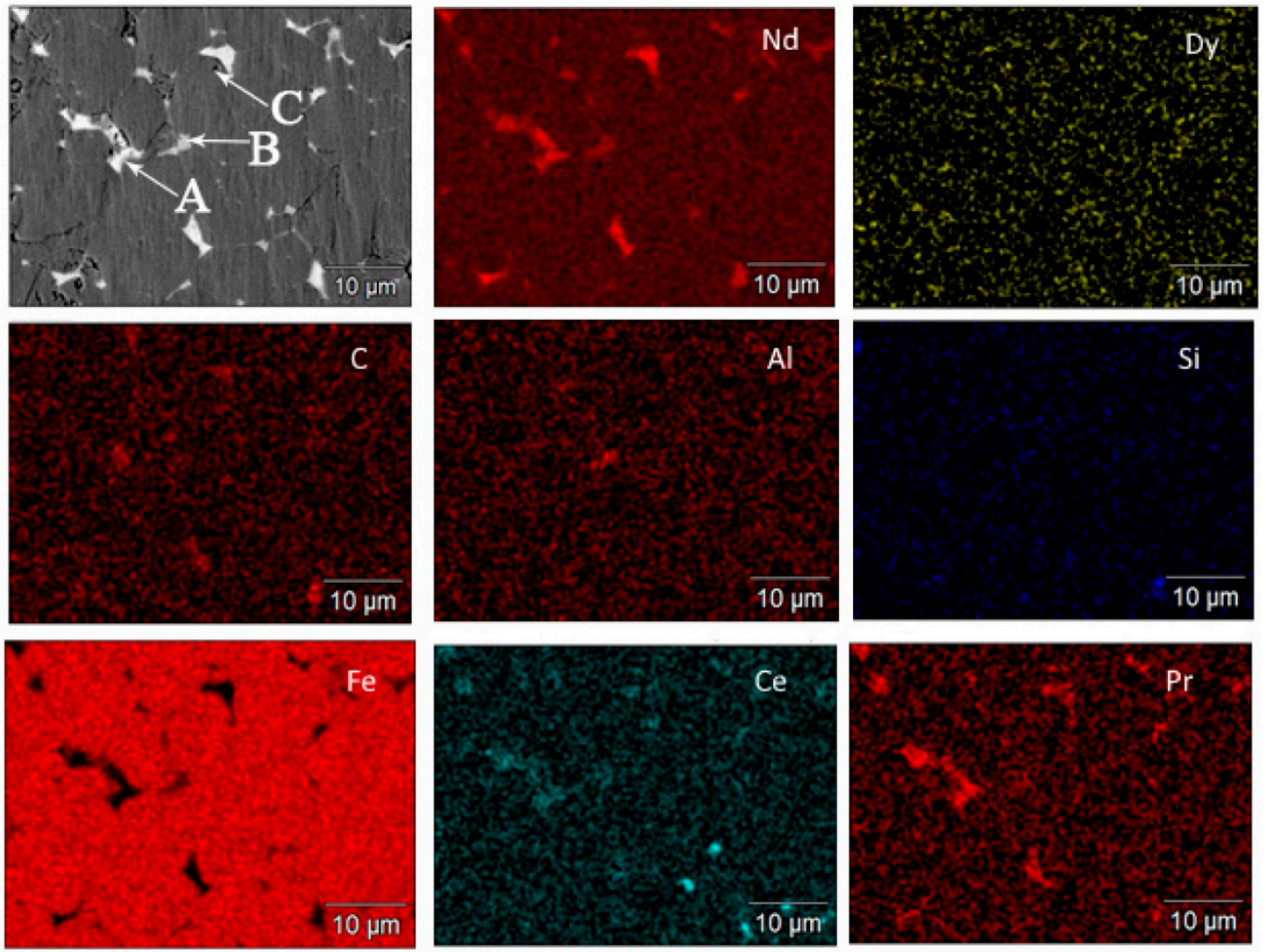

Figure 7. High-resolution EDX mapping of the NdFeB magnet scrap [60]; published by Elsevier, 2020.

\section{Hydrometallurgical Processes for Recovering REEs from the NdFeB Magnet Scrap}

For the treatment of NdFeB permanent magnet scrap, many hydrometallurgical processes have been developed or are under development. A brief schematic diagram of these hydrometallurgical processes is shown in Figure 8. The principle processes employed during hydrometallurgical treatment of REEs resources mainly include leaching, and REEs separation process [62-64]. In the present study, leaching technologies used for $\mathrm{NdFeB}$ permanent magnet scrap include selective leaching process and complete leaching process, which are followed by REEs separation technologies consisting of precipitation process, solvent extraction process and ionic liquids extraction process. 

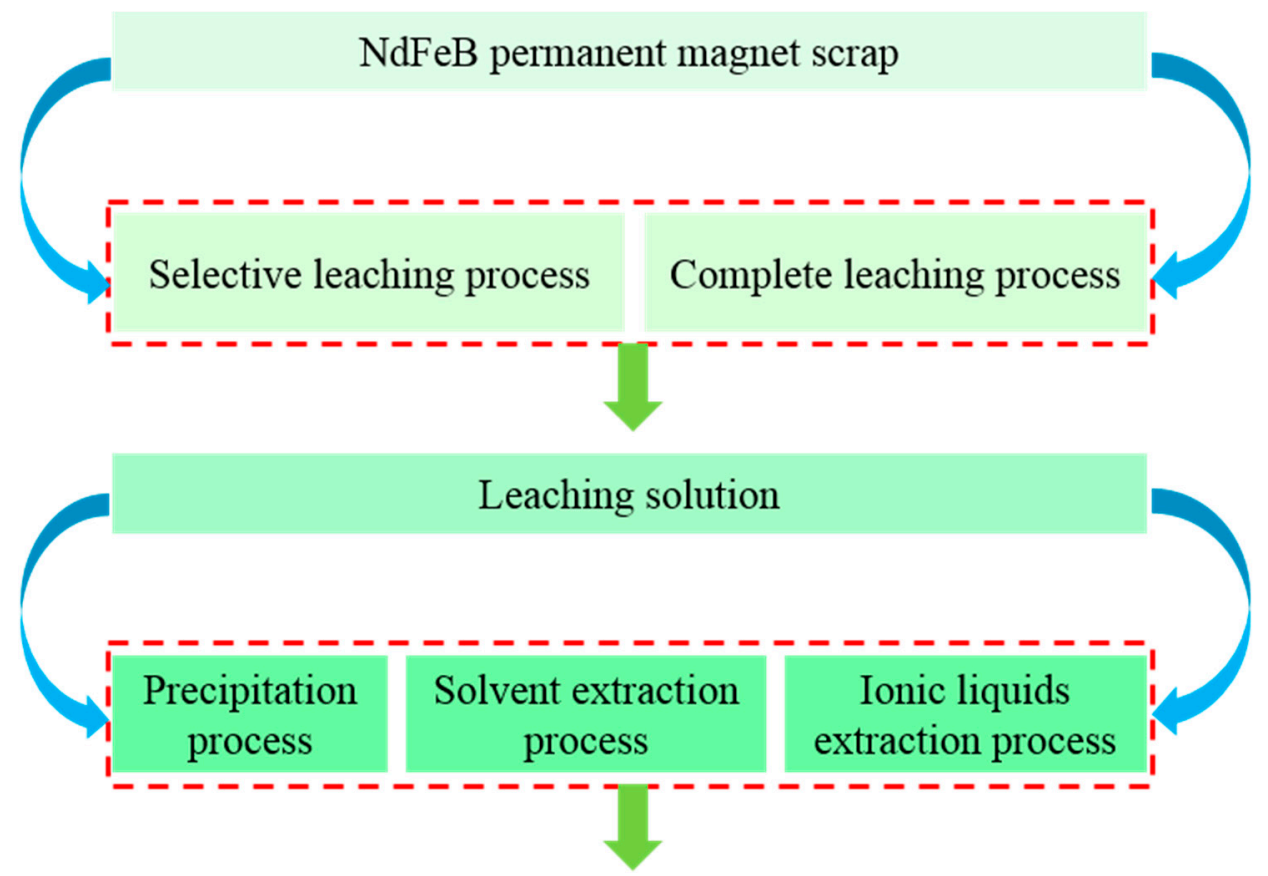

\section{Recovery of REEs}

Figure 8. Schematic diagram of hydrometallurgical processes.

\subsection{Leaching Technologies Used for NdFeB Permanent Magnet Scraps}

Leaching is always the first step to dissolve the REEs in the magnet scraps $[65,66]$. According to the complexity level, different dissolution methods are used. Dissolution of the magnet scrap can be performed in two different ways: (1) selective leaching of $\mathrm{NdFeB}$ permanent magnet scrap depending on the solubility of metal at different conditions, (2) complete leaching of the NdFeB permanent magnet scrap.

\subsubsection{Selective Leaching Process}

The selective leaching process depends on the solubility between REEs and Fe. In order to improve the selectivity and efficiency, many pretreatment processes (e.g., roasting) have been carried out.

Thermal oxidation is often used to improve the selectivity before leaching [63,64]. During the thermal oxidation process, the relatively easily soluble $\mathrm{Nd}_{2} \mathrm{O}_{3}$ and insoluble $\mathrm{Fe}_{2} \mathrm{O}_{3}$ were formed to hinder the leaching of $\mathrm{Fe}$ in acidic solution. It was reported that, after oxidative roasting at $900{ }^{\circ} \mathrm{C}$ for $360 \mathrm{~min}$, the roasted sample was leached by $0.02 \mathrm{~mol} / \mathrm{L} \mathrm{HCl}$ at $180{ }^{\circ} \mathrm{C}$ for $120 \mathrm{~min}$, and the recovery of REEs and iron were $99 \%$ and 5\%, respectively $[67,68]$. Similar research [59] reported that, under conditions of oxidative roasting at $900{ }^{\circ} \mathrm{C}$ for $480 \mathrm{~min}$ and subsequent dissolution with $37 \mathrm{wt} . \% \mathrm{HCl}$ at $80{ }^{\circ} \mathrm{C}$ for $900 \mathrm{~min}$, the leaching percentages of $\mathrm{Nd}$ and $\mathrm{Dy}$ were both above $90 \%$. According to Kumari et al., the roasting of the magnet enhances the selectivity as well as the leaching efficiency. $98 \%$ of the REEs were selectively leached and iron oxide was left in the leaching residue under the conditions of roasting temperature of $850{ }^{\circ} \mathrm{C}$, roasting time of $360 \mathrm{~min}, \mathrm{HCl}$ concentration of $0.5 \mathrm{~mol} / \mathrm{L}$, leaching temperature of $95^{\circ} \mathrm{C}$, and leaching time of $300 \mathrm{~min}$. At leaching temperature of $75-95{ }^{\circ} \mathrm{C}$, the leaching of REEs follows the mixed controlled kinetic model with Ea of $30.1 \mathrm{~kJ} / \mathrm{mol}$ [69]. An identical leaching process with $\mathrm{HNO}_{3}$ as leaching agent was carried out and very similar results were obtained. Leaching with $\mathrm{HCl}$ and $\mathrm{HNO}_{3}$ in the presence of a concentrated chloride or nitrate matrix (3.75 mol/L of $\mathrm{CaCl}_{2}$ or $7.5 \mathrm{~mol} / \mathrm{L}$ of $\mathrm{NH}_{4} \mathrm{NO}_{3}$ ) was also tested to prove that the leachate could be used directly into a cheap solvent extraction systems to further extract and purify the REEs [70,71]. However, during 
the oxidation roasting process, the inevitable formation of neodymium-iron mixed oxide $\left(\mathrm{NdFeO}_{3}\right)$ will hinder the leaching of $\mathrm{Nd}$. To avoid the formation of $\mathrm{NdFeO}_{3}$, Martina et al. [72], roasting the $\mathrm{NdFeB}$ scrap in Ar atmosphere at $\mathrm{PO}_{2} \leqq 10-20 \mathrm{~atm}$ with $5 \mathrm{wt} . \% \mathrm{C}$ at $1400{ }^{\circ} \mathrm{C}$ for $120 \mathrm{~min}$. The results showed that the roasting sample included a metallic Fe phase and B-Dy-Nd phase. After the recovery of metallic iron by mechanical treatment, the REEs in the NdFeB scrap can be completely dissolved in the water-containing ionic liquid [Hbet][Tf $\left.{ }_{2} \mathrm{~N}\right]$ in $20 \mathrm{~min}$.

Rabatho et al. described a process for recovering $\mathrm{Nd}$ and $\mathrm{Dy}$ from a $\mathrm{NdFeB}$ manufacturing process via selective leaching process. The leaching agents were $1 \mathrm{~mol} / \mathrm{L} \mathrm{HNO}_{3}+0.3 \mathrm{~mol} / \mathrm{L} \mathrm{H}_{2} \mathrm{O}_{2}$. The leaching of $\mathrm{Nd}$ and Dy was up to $98 \%$ and $81 \%$, respectively, and the leaching of Fe was below $15 \%$ [73]. Another research reported that the pretreatment of the corrosion process increased the selectivity between $\mathrm{Nd}$ and $\mathrm{Fe}$ at room temperature, and nearly $100 \%$ of $\mathrm{Nd}$ was recovered from NdFeB magnet scrap [74].

An alkaline treatment of $\mathrm{NdFeB}$ magnet at various $\mathrm{NaOH}$ concentration was carried out. When the equivalents of $\mathrm{NaOH}$ was 10 , the leaching of $\mathrm{Nd}$ and $\mathrm{Dy}$ was $91.6 \%$ and $94.6 \%$, respectively, and the leaching of $\mathrm{Fe}$ of $24.2 \%$, resulting in the highest selective leaching efficiency [60]. Using a sample prepared under the grinding and alkaline roasting treatments, $94.2 \%, 93.1 \%, 1.0 \%$ of Nd, Dy, Fe can be selectively leached at $90{ }^{\circ} \mathrm{C}$ in $1 \mathrm{~mol} / \mathrm{cm}^{3}$ acetic acid solution with $1 \%$ pulp density [75].

Itoh et al. proposed a new recovery process for REEs by selective chlorination roasting of the $\mathrm{NdFeB}$ magnet and leaching of the roasted sample in distilled water, the leaching of REEs reached $87 \%$ when chlorinating at $300{ }^{\circ} \mathrm{C}$ for $3 \mathrm{~h}$, with a nearly negligible content of $\mathrm{Fe}$ in the solution [30]. Önal et al. developed a sulfation selective roasting followed by water leaching process. A suitable selective roasting and water leaching treatment showed that $95-100 \% \mathrm{Nd}, \mathrm{Dy}, \mathrm{Pr}, \mathrm{Gd}, \mathrm{Tb}$, and Eu were leached, while Fe remained in the leaching residue to form a marketable $\mathrm{Fe}_{2} \mathrm{O}_{3}$-based by-product [60]. This process offers a simple and controllable processing alternative that is completely compatible with the existing REEs production process [76]. It also faces some disadvantages; one disadvantage was that the sulfation roasting required relatively high temperature $\left(750-800^{\circ} \mathrm{C}\right)$. The other disadvantage was related to the low solubility limit of REE sulfate, which may have negative impact on process capability. More seriously, these solubility limitations can also cause problems in subsequent downstream processes, where organic/inorganic solvents are introduced into the leachate at higher temperatures (e.g., 60-80 ${ }^{\circ} \mathrm{C}$ ) [34]. In order to avoid those disadvantages, they replaced sulfuric acid with nitric acid. Similar to sulfation roasting, the REEs nitrates are expected to remain soluble, and the solubility limit of the REEs nitrates is higher than that of its sulfate counterparts [55].

Venkatesan et al. reported an electrochemical route to selectively leach REEs from the NdFeB magnet scrap. At first, part of the magnet scrap was leached by $\mathrm{HCl}$. A portion of the leachate was collected with the undissolved magnet scrap on the anolyte side of the two-chamber reactor (Figure 9), which was separated by an anion exchange membrane, and the catholyte was composed of $\mathrm{NaCl}$ solution. The $\mathrm{Fe}(\mathrm{II})$ in the leachate was oxidized and precipitated as $\mathrm{Fe}(\mathrm{OH})_{3}$, and more than $95 \%$ of the REEs were dissolved in the solution [77]. In addition, when the NdFeB magnet scrap was completely leached with $\mathrm{HCl}$, the $\mathrm{Fe}(\mathrm{II})$ in the leachate can be selectively oxidized to $\mathrm{Fe}(\mathrm{III})$ [78]. In another research, a route for recovering REEs from $\mathrm{NdFeB}$ magnet scrap based on electrochemical leaching was also verified (Figure 10). NdFeB magnet scrap was taken as an anode along with an inert anode in an electrochemical reactor $\left(\mathrm{NH}_{4} \mathrm{Cl}\right.$ was used as the electrolyte) to ensure the elements in the magnet scrap into the respective hydroxides, then leaching with $\mathrm{HCl}$. The leaching of REEs and Co exceed 97\% with Fe was left in the leaching residue [79].

The selective leaching process is considered to be a relatively commercial process for recovering REEs from NdFeB permanent magnet scrap in spite of several disadvantages [80-83]. The major shortcoming of this process is insufficient separation efficiency, and it is hard to avoid the unwanted elements going into a solution. 

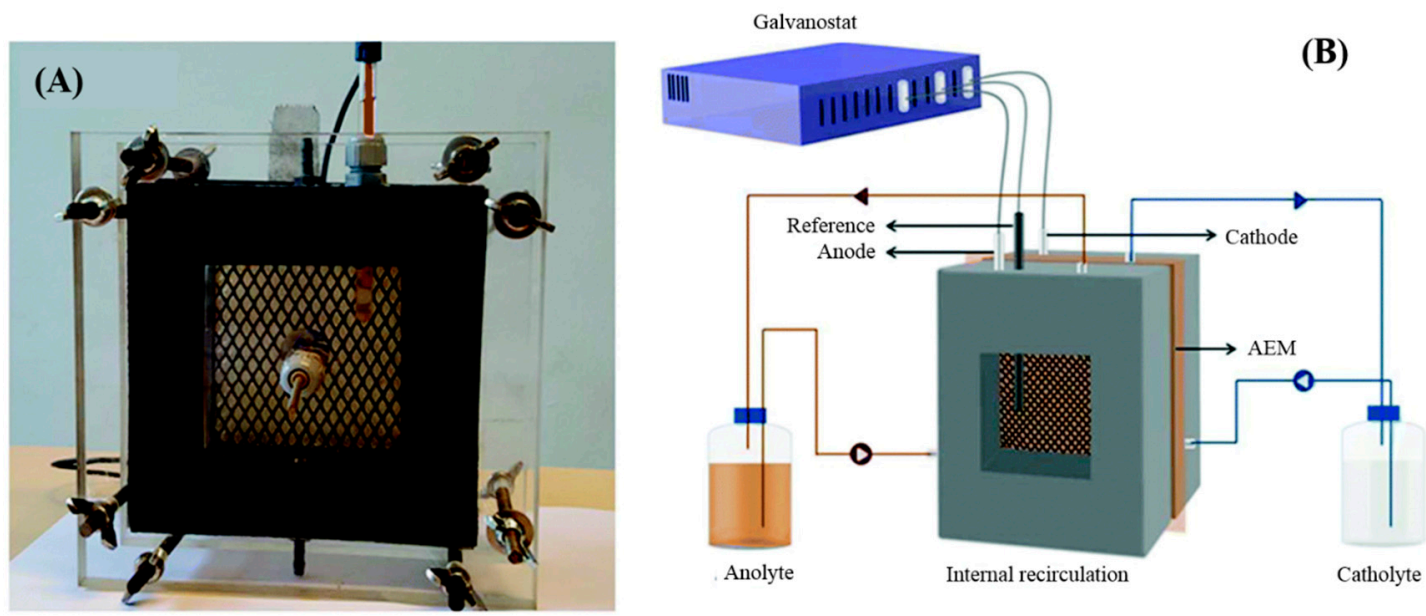

Figure 9. (A) Photo and (B) schematic illustration of the membrane electrochemical reactor [77]; published by Royal Society of Chemistry, 2018.

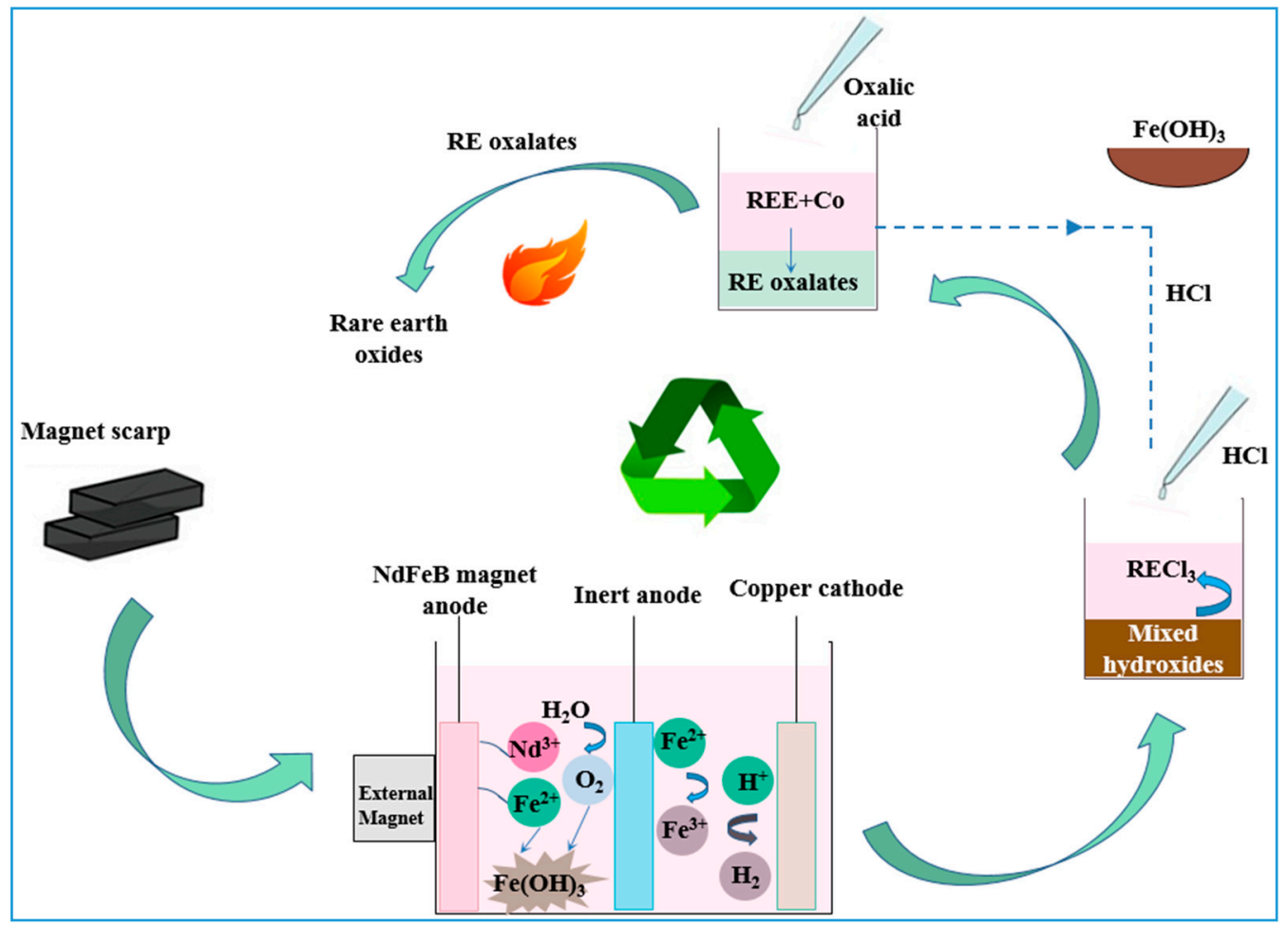

Figure 10. Process flowsheet for the proposed recycling scheme [79]; published by American Chemical Society, 2018.

\subsubsection{Complete Leaching Process}

The aim of complete leaching process is to dissolve the magnet completely. According to Itakura et al., a commercially available Ni-coated NdFeB sintered magnet was leached by $3 \mathrm{~mol} / \mathrm{L} \mathrm{HCl}$ and $0.2 \mathrm{~mol} / \mathrm{L} \mathrm{H}_{2} \mathrm{C}_{2} \mathrm{O}_{4}$ at $110{ }^{\circ} \mathrm{C}$ for $6 \mathrm{~h} \mathrm{[53].} \mathrm{The} \mathrm{NdFeB}$ magnet went into a solution and $\mathrm{Nd}$ was formed a precipitate of neodymium oxalate and more than $99 \%$ of $\mathrm{Nd}$ was recovered. By addition of $\mathrm{Ca}(\mathrm{OH})_{2}$, the $\mathrm{B}$ can be recovered from the highly acidic waste water by formation of $\mathrm{CaB}_{2} \mathrm{O}_{5} \cdot \mathrm{H}_{2} \mathrm{O}[84,85]$. Abrahami et al. indicated the feasibility of directly leaching of $\mathrm{NdFeB}$ magnet scrap by $\mathrm{H}_{2} \mathrm{SO}_{4}$, although the composition of the scrap was complex, the combination of different steps still achieved a high recovery with a relatively pure rare earth double salt product (98.4\%). Many impurities (mainly iron) were also dissolved in sulfuric acid, and these impurities can be removed after precipitation of 
REEs [86]. A decomposition and leaching process of $\mathrm{NdFeB}$ permanent magnet scrap by oxidation roasting and sulfuric acid leaching were examined by Yoon et al. [87]. Under the conditions of roasting temperature of $500{ }^{\circ} \mathrm{C}$ for sintered scrap and of $700{ }^{\circ} \mathrm{C}$ for bonded scrap followed by $\mathrm{H}_{2} \mathrm{SO}_{4}(2 \mathrm{~mol} / \mathrm{L})$ leaching at $50{ }^{\circ} \mathrm{C}$ for $120 \mathrm{~min}$, the leaching of $\mathrm{Nd}$ was over $99.4 \%$, but $95.7 \%$ of Fe was also dissolved into the solution, which was similar to the results obtained by Layman and Palmer [88]. $\mathrm{HCl}$ and $\mathrm{HNO}_{3}$ could also be used to completely leach magnet scrap [89]. The feasibility of organic acids for leaching REEs was verified by Gergoric et al. the results showed that after leaching with $1 \mathrm{~mol} / \mathrm{L}$ acetic acid or citric acid at $25^{\circ} \mathrm{C}$ for $24 \mathrm{~h}$, the leaching of REEs exceeded $95 \%$ [90].

Electrochemical leaching was investigated to leach $\mathrm{Fe}$ and REEs from NdFeB magnet scrap with $\mathrm{H}_{2} \mathrm{SO}_{4}$ and $\mathrm{H}_{2} \mathrm{C}_{2} \mathrm{O}_{4}$ by Makarova et al. [60]. The scanning Kelvin probe force microscopy results showed that the Local Volta potential difference between $\mathrm{Nd}_{2} \mathrm{Fe}_{14} \mathrm{~B} \phi$-phase and the Nd-rich anodic phases exceeded $500 \mathrm{mV}$, which indicated preferential selective leaching of the Nd-rich phase. A 3D printed Ti basket (Figure 11) was used to leach metals from the magnet scrap, the experimental results found that the acid concentration and current density strongly affected the leaching of REEs, and the addition of oxalic acid reduced the energy consumption and improved the recovery of REEs. The mechanism of dissolution was shown in Figure 12, fast and preferential leaching occurs in the less noble Nd-rich phases located around the Fe-rich $\mathrm{Nd}_{2} \mathrm{Fe}_{14} \mathrm{~B}$ grains ( $\phi$-phase), then whole grains of the $\phi$-phase eventually falls off from the surface.

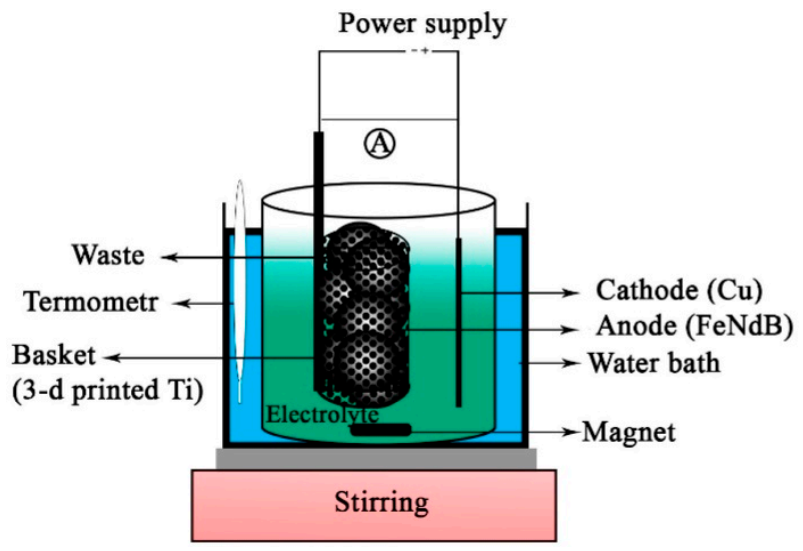

Figure 11. Schematic picture of electro-leaching in a Ti basket [60]; published by Elsevier, 2020.
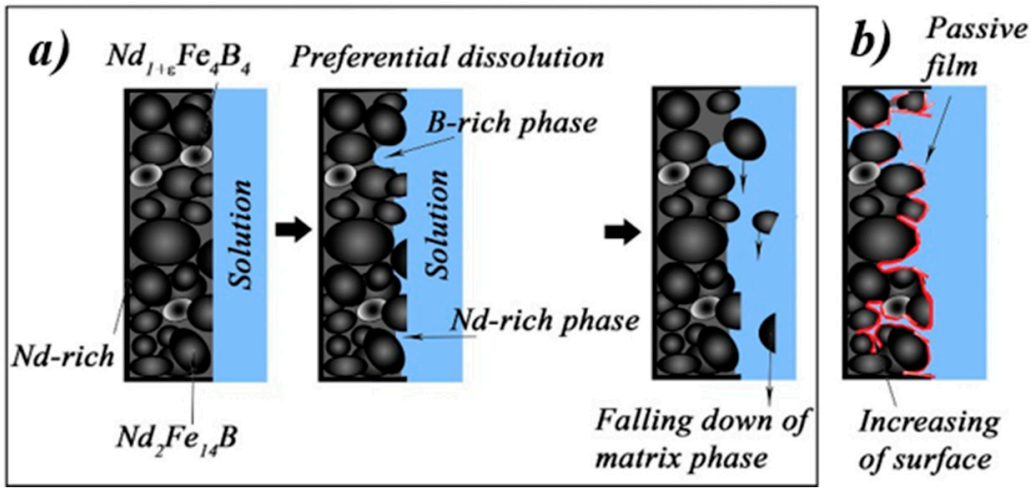

Figure 12. Schematic illustration of leaching process on the surface of $\mathrm{NdFeB}$ magnet scrap in (a) $\mathrm{H}_{2} \mathrm{SO}_{4},(\mathbf{b})$ mixture of $\mathrm{H}_{2} \mathrm{SO}_{4}$ and $\mathrm{H}_{2} \mathrm{C}_{2} \mathrm{O}_{4}$ [60]; published by Elsevier, 2020.

Auerbach et al. [82] suggested recovering REEs from NdFeB magnet scrap by means of bioleaching with various bacteria. The Acidithiobacillus ferrooxidans and Leptospirillum ferrooxidans was confirmed to have highest leaching efficiencies with the leaching of Dy, Nd, and $\operatorname{Pr}$ of $86 \%, 91 \%$, and $100 \%$, respectively. However, due to the non-selective leaching of bacteria, further separation and purification 
processes should be carried out. Precipitation with concentrated $\mathrm{H}_{2} \mathrm{C}_{2} \mathrm{O}_{4}$ and a two-step extraction process with the ionic liquid Cyphos IL 101 and subsequent treatment with DEHPA are considered to be the most effective methods. Extraction rates up to $100 \%$ with a purity of $98 \%$ were achieved.

The complete leaching process features a simple and easy operation, but the main shortcomings of this process include relatively high consumption of leaching agent and subsequent difficulties in removing impurities.

\subsection{REEs Separation Technologies Used for NdFeB Permanent Magnet Scrap}

Leaching liquor obtained through various leaching processes should be treated by different separation techniques such as precipitation, solvent extraction, and ionic liquids extraction to selectively separate REEs from the liquor $[83,90]$. Note that precipitation and solvent extraction can also use a combination of these. A brief comparison of these separation technologies is shown in Table 3.

Table 3. Comparison of different REEs separation technologies for NdFeB permanent magnet scraps.

\begin{tabular}{|c|c|c|}
\hline Methods. & Advantages & Disadvantages \\
\hline Precipitation & $\begin{array}{l}\text { Low cost } \\
\text { The process is simple }\end{array}$ & $\begin{array}{c}\text { Low recovery } \\
\text { Product is impurity } \\
\text { Hard to obtain single REE }\end{array}$ \\
\hline Solvent extraction & $\begin{array}{c}\text { High recovery } \\
\text { Can obtain high purity single REE }\end{array}$ & $\begin{array}{c}\text { High cost } \\
\text { The process is complicate } \\
\text { Generation of large amount of waste }\end{array}$ \\
\hline Ionic liquids extraction & $\begin{array}{c}\text { High recovery } \\
\text { Can obtain high purity single REE } \\
\text { Efficient } \\
\text { Environmentally friendly }\end{array}$ & $\begin{array}{l}\text { High cost } \\
\text { It is difficult to prepare ionic liquids system }\end{array}$ \\
\hline
\end{tabular}

\subsubsection{Precipitation Process}

The precipitation methods could be classified into two categories, namely selective precipitation and co-precipitation. According to the leaching process, the principle flowsheets of the precipitation processes are shown in Figure 13.

The resulting leaching solution is treated by a precipitation method with $\mathrm{pH}$ changes to separate $\mathrm{Nd}$. Nd can usually be precipitated by direct methods such as fluoride method with $\mathrm{HF}$ and oxalate method with $\mathrm{H}_{2} \mathrm{C}_{2} \mathrm{O}_{4}[83,91]$. It has been found that strongly acidic solvents are suitable for the dissolution of $\mathrm{NdFeB}$ magnet scrap. However, these solvents cannot produce precipitation of the $\mathrm{Nd}$ compound. Therefore, some precipitating agents for $\mathrm{Nd}$ is needed. $\mathrm{NaCl}$, ethanol and $\mathrm{H}_{2} \mathrm{C}_{2} \mathrm{O}_{4}$ were used as precipitating agents by Itakura et al. It was indicated that these precipitating agents led to the formation of insoluble $\mathrm{Nd}$ compounds. However, Fe was contained in the precipitate when $\mathrm{H}_{2} \mathrm{SO}_{4} / \mathrm{NaCl}$ or $\mathrm{H}_{2} \mathrm{SO}_{4} /$ ethanol were used as precipitating agents. But in a mixed aqueous solvent of $3.0 \mathrm{~mol} / \mathrm{L} \mathrm{HCl}$ and $0.2 \mathrm{~mol} / \mathrm{L} \mathrm{H}_{2} \mathrm{C}_{2} \mathrm{O}_{4}$ via hydrothermal treatment at $110{ }^{\circ} \mathrm{C}$ for $360 \mathrm{~min}$. About $99 \%$ of $\mathrm{Nd}$ contained in the magnet scrap was recovered as $\mathrm{Nd}_{2}\left(\mathrm{C}_{2} \mathrm{O}_{4}\right)_{3} \cdot \mathrm{xH}_{2} \mathrm{O}$ with a purity of $99.8 \%$ [56]. Mechano-chemical treatment with a mixed aqueous solution of $\mathrm{HCl}$ and $(\mathrm{COOH})_{2}$ has been proved to be an efficient method that can selectively recover REEs as oxalate from NdFeB magnet scrap without external heating. The optimal concentrations of $\mathrm{HCl}$ and $(\mathrm{COOH})_{2}$ were found to be $0.2 \mathrm{~mol} / \mathrm{L}$ and $0.25 \mathrm{~mol} / \mathrm{L}$, respectively. The recovery and purity of REEs were $95.3 \%$ and $95.0 \%$, respectively [92] Over $99 \%$ of $\mathrm{Nd}$ can be recovered from a Fe-Nd solution by using $\mathrm{H}_{3} \mathrm{PO}_{4}$ and ascorbic acid via selective precipitation process [31]. $\mathrm{Nd}$ also can be recovered as $\mathrm{Mn}_{2} \mathrm{O}_{3}$-type $\mathrm{Nd}_{2} \mathrm{O}_{3}$, with the recovery of $\mathrm{Nd}$ of $97 \%$ via oxalic acid precipitation from $\mathrm{NdFeB}$ magnet scrap [74]. 
(a)

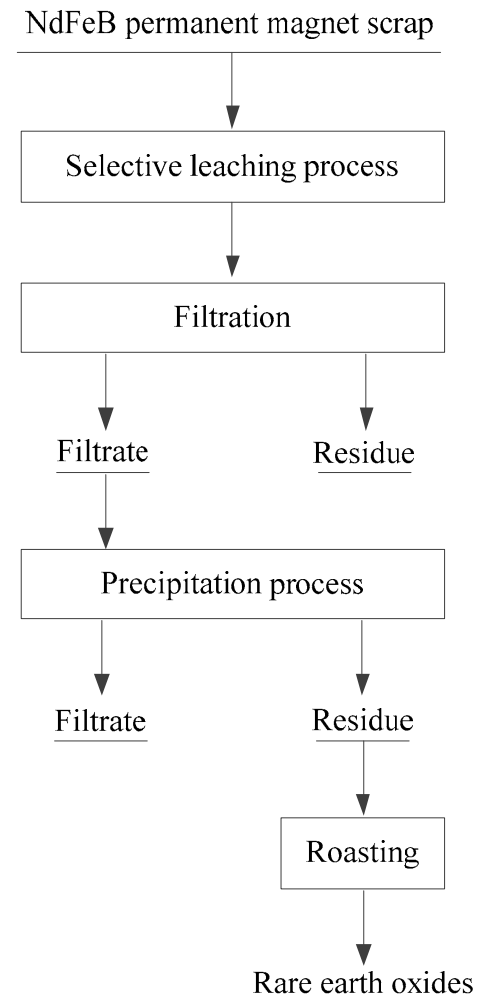

(b)

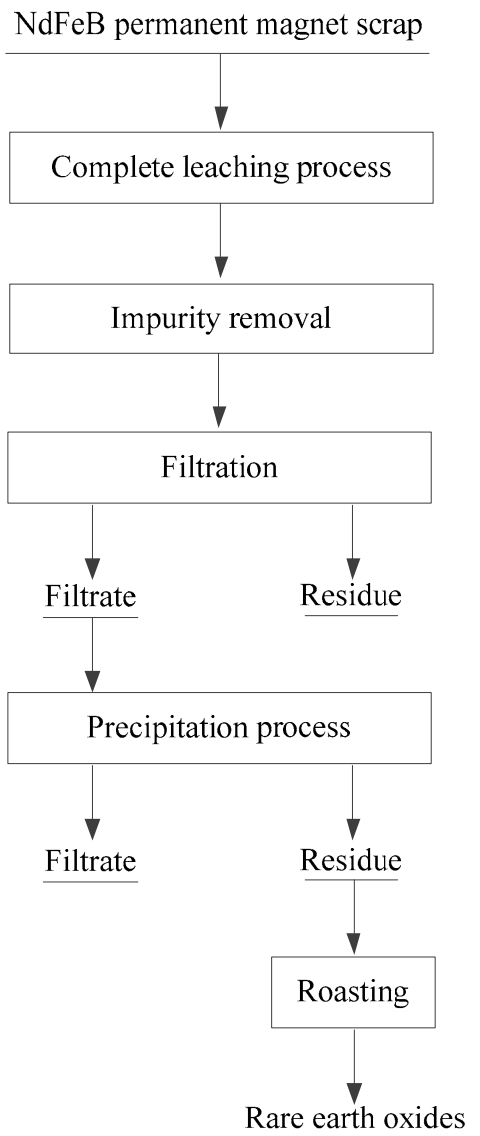

Figure 13. Principle flow of precipitation processes. (a) selective precipitation (b) co-precipitation.

Rabatho et al. tried to recover REEs from NdFeB magnetic waste sludge via selective precipitation process. Fe impurity in solution was first removed as $\mathrm{Fe}(\mathrm{OH})_{3}$ with losses of $\mathrm{Nd}$ and $\mathrm{Dy}$ of $22.50 \%$ and $23.65 \%$, respectively, by addition of $\mathrm{NaOH}$ solution to control the solution $\mathrm{pH}$ of 3 , then $\mathrm{Nd}$ and Dy were precipitated by addition of $\mathrm{H}_{2} \mathrm{C}_{2} \mathrm{O}_{4} .91 .5 \%$ of $\mathrm{Nd}$ and $81.8 \%$ of Dy were recovered from the solution. After roasting the $\mathrm{Nd}$ and Dy containing precipitate at $800{ }^{\circ} \mathrm{C}$, an $\mathrm{Nd}_{2} \mathrm{O}_{3}$ product with purity of $68 \%$ could be obtained, and the final recovery of $\mathrm{Nd}$ and Dy of $69.7 \%$ and $51 \%$ achieved, respectively [73]. Similarly, Kikuchi et al. researched precipitation of $\mathrm{Fe}^{3+}$ from $\mathrm{NdFeB}$ magnet scrap $\mathrm{HNO}_{3}$ leaching solution by adjusting $\mathrm{pH}$ to 4.3 with the addition of $\mathrm{NaOH}$ [93]. As shown in Figure 14, the REEs were selectively dissolved from a crushed and roasted NdFeB magnet by acid, then purified by solvent extraction and precipitated as pure REE oxalate salt [56].

Although these methods can effectively separate $\mathrm{Nd}$ from other metals, due to the difficulty of filtering $\mathrm{NdF}_{3}$ (because of the addition of $\mathrm{HF}$ ), the production cost of $\mathrm{Nd}$ oxalate is high and non-selective, so it is not preferred. Double salt precipitation $\left(\mathrm{Nd}_{2}\left(\mathrm{SO}_{4}\right)_{3}, \mathrm{Na}_{2} \mathrm{SO}_{4} \cdot 6 \mathrm{H}_{2} \mathrm{O}\right)$ may be an option for the precipitation of $\mathrm{Nd}$ with $\mathrm{NaOH}$, and the REEs can be separated from Fe inexpensively without filtration problems. $\mathrm{Nd}$ was successfully separated from the optimized $\mathrm{H}_{2} \mathrm{SO}_{4}$ leaching solution and $\mathrm{Nd}$ was separated in the form of heavy salt precipitation with a heavy salt content of $75.41 \%$ [89]. Although the composition of NdFeB magnet scrap is complex, the combination of different steps makes it possible to obtain a relatively pure rare earth double salt product $(98.4 \%)$ with a high recovery by using the precipitation method [82,94]. 


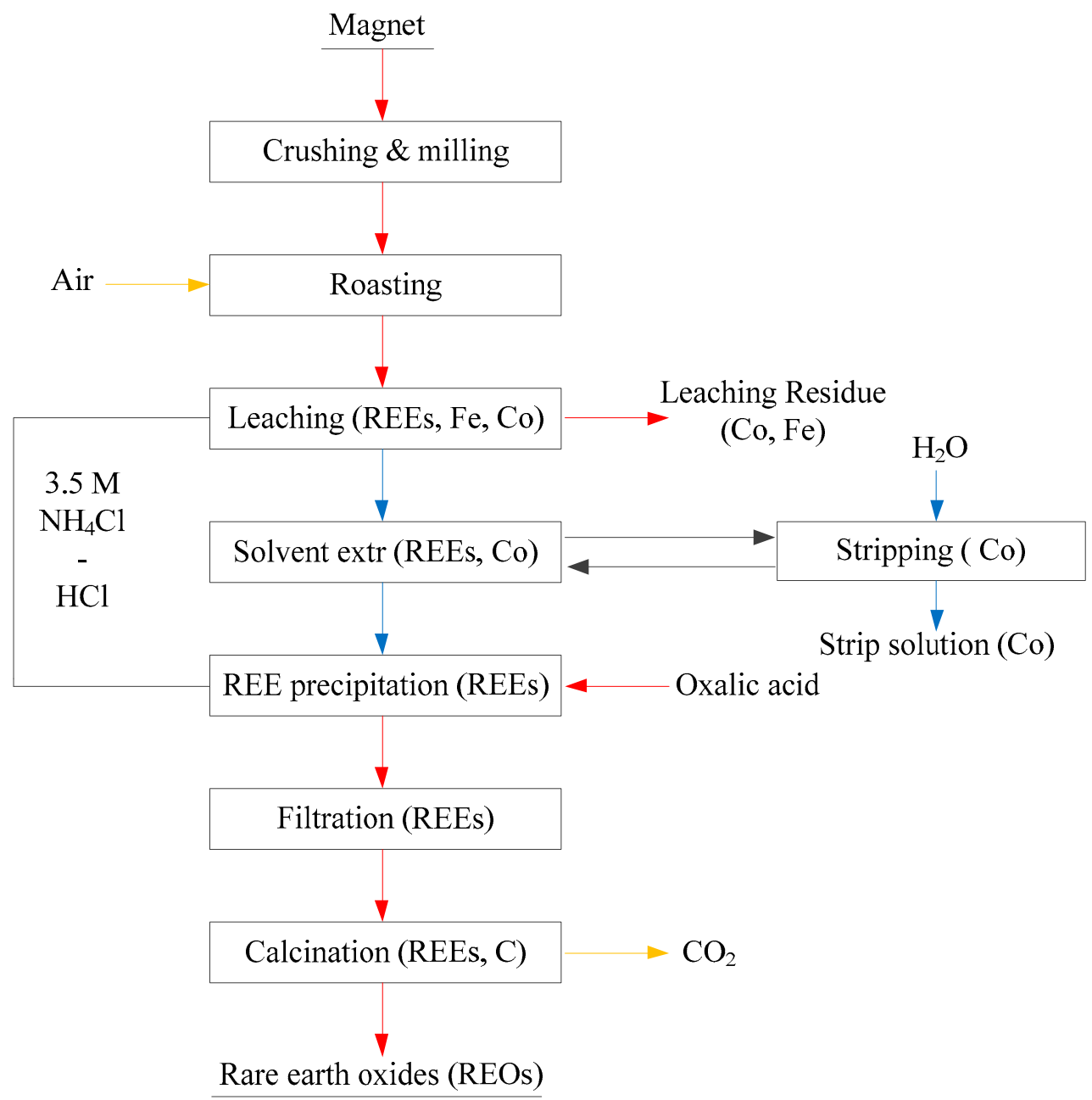

Figure 14. Flow chart of the recycling scheme. Yellow arrows: gas steams, blue arrows: aqueous streams, black arrows: ionic liquid steam, and red arrows: solid streams [56]; published by Royal Society of Chemistry, 2014.

Compared with the selective precipitation method, the co-precipitation method can simultaneously recover the valuable elements in the $\mathrm{NdFeB}$ magnet leaching solution $[37,95,96]$. Using this method, a composite powder containing REEs, Fe and Co can be obtained. The powder can be directly used as raw material for the preparation of all types of $\mathrm{NdFeB}$ magnetic powder with controlling to add desirable elements. Based on the thermodynamic simulation and calculation of MATLAB in the $\mathrm{H}_{2} \mathrm{C}_{2} \mathrm{O}_{4}-\mathrm{NH}_{3}$ co-precipitation system, an effective co-precipitation route (see Figure 15) was carried out to obtain a composite powder containing more than $99.4 \%$ of valuable elements, such as $\mathrm{Fe}_{2} \mathrm{O}_{3}$, $\mathrm{Fe}_{2} \mathrm{O}_{3} \cdot \mathrm{Nd}_{2} \mathrm{O}_{3}$, and $\mathrm{Pr}_{2} \mathrm{CoO}_{4}$. These valuable elements can be directly used as raw materials for the preparation of recycled $\mathrm{NdFeB}$ magnetic powder [37]. 


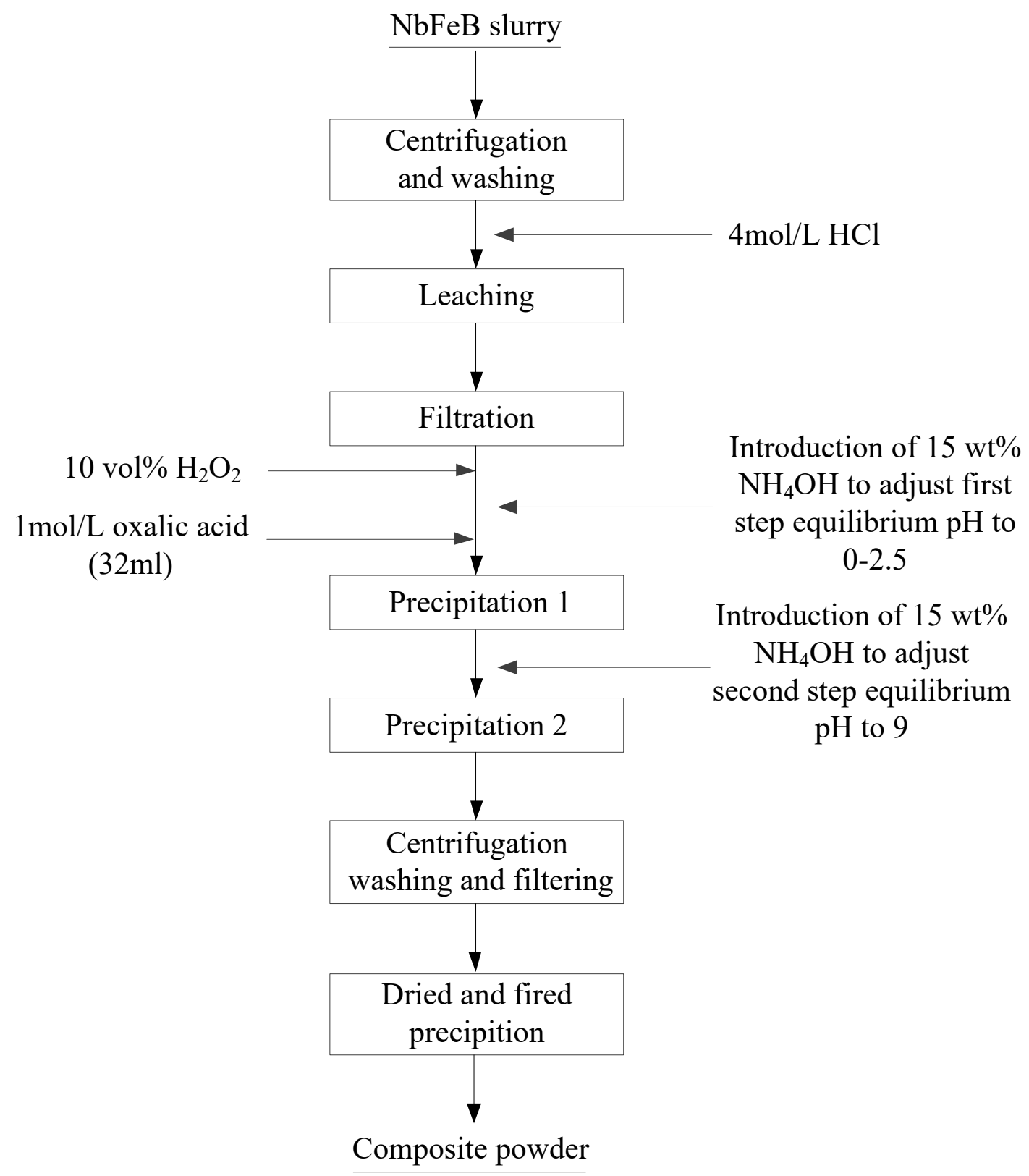

Figure 15. Scheme for the synthesis of a composite powder from NdFeB magnet scrap leaching solution using a co-precipitation method [37]; published by Elsevier, 2014.

\subsubsection{Solvent Extraction Process}

Because of the chemical similarity of REEs, separation of each other from different sources is one of the greatest challenges in the recycling of REEs [97,98]. Among various separation techniques, solvent extraction can be an effective method for separating and extracting individual metal or obtaining mixed solutions and compounds. Solvent extraction is a process for the selective extraction of a target component from an aqueous solution with one or more water immiscible organic reagents. To develop feasible and eco-friendly processes, extensive studies have been carried out for the extraction of various REEs by solvent extraction process using different organic extractants. Corresponding salient features of extractants are presented in Table 4. According to the solvent extraction mechanism, the solvent extraction process could be classified into four categories, including acidic solvent extraction (cationic solvent extraction), ion-pair solvent extraction (anion solvent extraction), neutral solvent extraction, 
and synergetic solvent extraction [99]. The properties of their extraction and separation, the formation of complex, separation factor, etc., have been highlighted as given below.

Table 4. Different organic solvents used for the extraction of REEs.

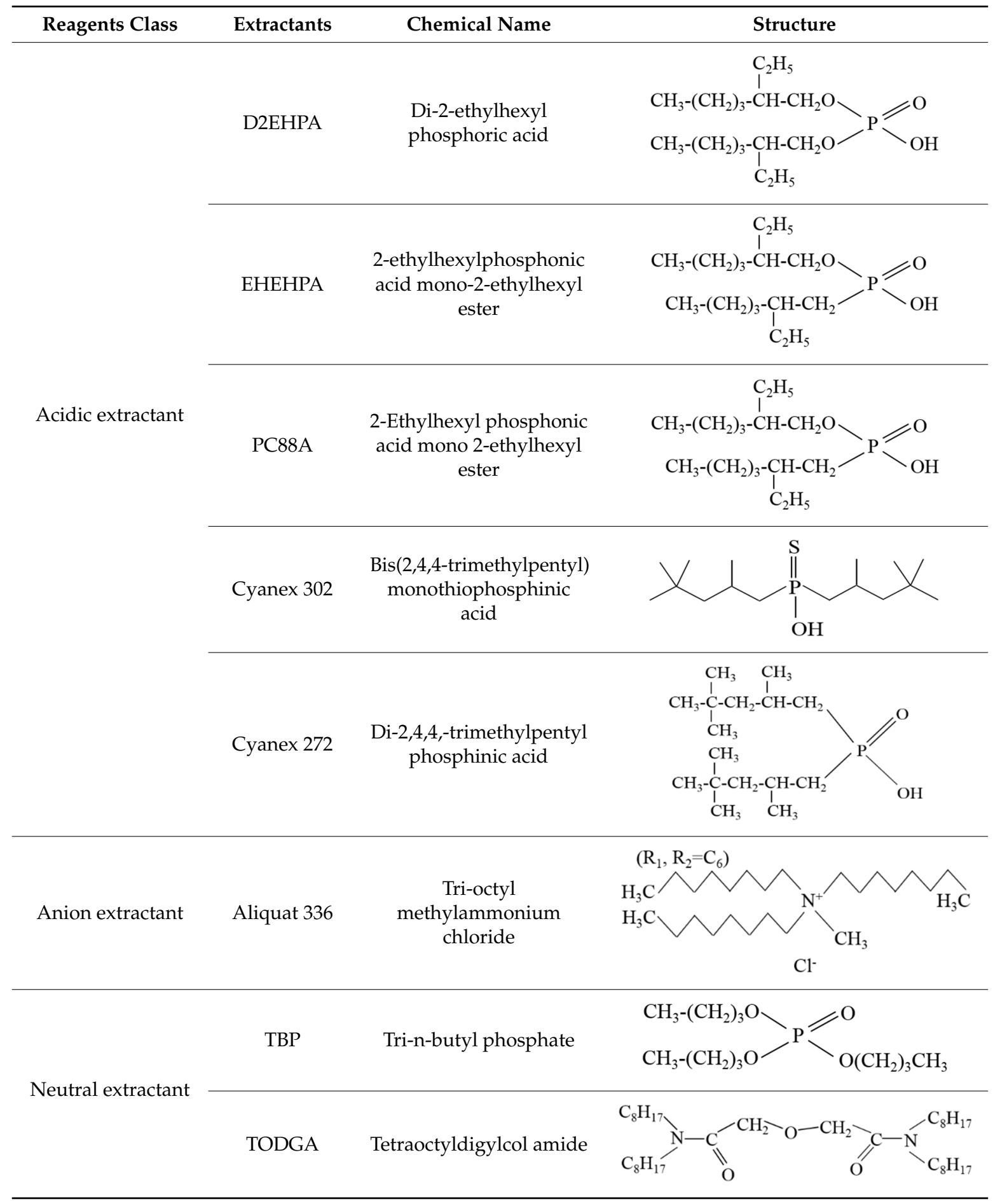




\section{Acidic Solvent Extraction}

Acidic solvent extraction uses weak organic acid as the extractants. Acidic extractants are used to extract and separate REEs because they form cationic species in aqueous solution. The general extraction mechanism shows as the following equation [99]:

$$
\mathrm{M}^{\mathrm{n}+}+\mathrm{nHA}=\mathrm{MA}_{\mathrm{n}(\mathrm{org})}+\mathrm{nH}^{+}(\mathrm{aq})
$$

Various acidic organophosphorous extractants have been used in REEs extraction processes. D2EHPA, di-(2-ethylhexyl) phosphoric acid (HDEHP), PC88A and EHEHPA are the most widely used solvents $[100,101]$. $\mathrm{HCl}, \mathrm{H}_{2} \mathrm{SO}_{4}$ and $\mathrm{HNO}_{3}$ were utilized as extraction media for the extraction of $\mathrm{Nd}, \mathrm{Eu}$ and Tm using D2EHPA as an extractant. The results indicated that the equilibrium constants increased as the order: $\mathrm{Nd}<\mathrm{Eu}<\operatorname{Tm}[102,103]$. Proximate researches confirmed that the extraction results of lanthanides with D2EHPA from $\mathrm{HNO}_{3}$ were poorer than those from $\mathrm{HCl}$ and $\mathrm{H}_{2} \mathrm{SO}_{4}$ solutions [97]. The selectivity sequence for extracting REEs from $0.5 \mathrm{~mol} / \mathrm{L} \mathrm{HCl}$ solution with $0.75 \mathrm{~mol} / \mathrm{L}$ D2EHPA in toluene was $\mathrm{Lu}>\mathrm{Yb}>\mathrm{Tm}>\mathrm{Tb}>\mathrm{Eu}>\mathrm{Pm}>\mathrm{Pr}>\mathrm{Ce}>\mathrm{La}$, and the average separation factor of two adjacent REEs was 2.5 [104]. Although the REEs extraction efficiency of D2EHPA is very high, however, the difficulty of stripping the loaded extractant limits its utilization, especially for the extraction of heavy REEs. Lately, PC88A has attracted considerable attention to replace D2EHPA in the separation of REEs because of its higher separation factor for REEs (Table 5) [105]. Mohammadi et al. compared the separation of Nd, Dy and Y by D2EHPA and EPEHPA, the calculated separation factors at equilibrium $\mathrm{pH}=1$ indicated that D2EHPA was the most effective for separating $\mathrm{Nd}$ from $\mathrm{Y}$ and $\mathrm{Dy}$, and the EHEHPA showed the highest separation factor for Y and Dy [106].

Table 5. Separation factors for extraction of rare earths by DEHPA and PC88A.

\begin{tabular}{ccc}
\hline Rare Earths Pair & DEHPA & PC88A \\
\hline $\mathrm{Ce} / \mathrm{La}$ & 2.98 & 6.83 \\
\hline $\mathrm{Pr} / \mathrm{Ce}$ & 2.05 & 2.03 \\
\hline $\mathrm{Nd} / \mathrm{Pr}$ & 1.38 & 1.55 \\
\hline $\mathrm{Sm} / \mathrm{Nd}$ & 6.58 & 10.60 \\
\hline $\mathrm{Eu} / \mathrm{Sm}$ & 1.90 & 2.30 \\
\hline $\mathrm{Gd} / \mathrm{Eu}$ & 1.43 & 1.50 \\
\hline $\mathrm{Tb} / \mathrm{Gd}$ & 0.93 & 5.80 \\
\hline $\mathrm{Dy} / \mathrm{Tb}$ & 2.40 & 2.82 \\
\hline $\mathrm{Ho} / \mathrm{Dy}$ & 1.90 & 2.00 \\
\hline $\mathrm{Er} / \mathrm{Ho}$ & 2.25 & 2.73 \\
\hline $\mathrm{Er} / \mathrm{Y}$ & 1.37 & 1.43 \\
\hline $\mathrm{Tm} / \mathrm{Er}$ & 2.90 & 3.34 \\
\hline $\mathrm{Yb} / \mathrm{Tm}$ & 3.09 & 3.56 \\
\hline $\mathrm{Lu} / \mathrm{Yb}$ & 1.86 & 1.78 \\
\hline
\end{tabular}

The PC88A in kerosene exists in the form of dimer, and the extraction of Nd with PC88A can be expressed as the Equation (2) [107]. According to Lee et al., the extraction reaction of Nd with PC88A in chloride solution was identified by the graphical method as shown in Equation (3). They also observed that the distribution coefficients of $\mathrm{Nd}$ increased linearly with the equilibrium $\mathrm{pH}$ range of $0.62-1.01$ [108].

$$
\mathrm{Nd}^{3+}+\frac{3+x}{2} \mathrm{H}_{2} \mathrm{~A}_{2, \text { org }}=\mathrm{NdA}_{3} x H A_{\text {org }}+3 \mathrm{H}^{+}
$$




$$
\mathrm{Nd}^{3+}+1.5 \mathrm{H}_{2} \mathrm{~A}_{2, \text { org }}=\mathrm{Nd} \mathrm{A}_{3} \mathrm{H} \mathrm{A}_{\text {org }}+3 \mathrm{H}_{a q}{ }^{+}
$$

where $\mathrm{H}_{2} \mathrm{~A}_{2}$ and org represents the PC88A dimer and the organic phase, respectively.

The acidic extractants saponified with $\mathrm{NaOH}$ was researched to overcome the adversely affects caused by acid liberated during the acidic extraction process [106,109-111]. Moreover, partial saponification was preferred to avoid gel formation and the solution of the saponified extractant in the aqueous phase. Compared with Nd distribution coefficients of PC88A, the use of $40 \%$ saponified PC88A significantly improved the extraction of Nd [108]. A comparative study between Cyanex 302, PC88A and Cyanex 272, NaCyanex 302, NaPC88A and NaCyanex 272 for extracting Nd from a chloride solution has been conducted by Padhan et al. [33]. It was found that Cyanex 272 had the highest extraction rate and Cyanex 302 showed the lowest extraction rate. It is reported that the synthesized Primene 81R.Cyanex 572 ionic liquids can overcome the shortcomings of Cyanex 272 and Cyanex 572 of the sensitivity to $\mathrm{pH}$ value. $99.99 \%$ of $\mathrm{Nd}$ can be extracted from $\mathrm{Nd} / \mathrm{Tb} / \mathrm{Dy}$ containing aqueous by two stages counter-current extraction process with $0.30 \mathrm{~mol} / \mathrm{L}$ Primene $81 \mathrm{R} \cdot$ Cyanex 572 ionic liquid, and without $\mathrm{pH}$ adjusting [112]. Because saponified Cyanex 302 was an effective commercial reagent for extracting Nd, Padhan et al. [111] used it as the extractant to separate Nd and Dy. A maximum separation factor $\left(\mathrm{D}_{\mathrm{Dy}} / \mathrm{D}_{\mathrm{Nd}}\right)$ of 53.65 was observed at $\mathrm{pH}=1.2$. Extraction of $\mathrm{Dy}$ was $98 \%$ with co-extraction of $\mathrm{Nd}$ only $7.22 \%$ after two stages of counter current extraction in $0.125 \mathrm{~mol} / \mathrm{L} \mathrm{NaCyanex}$ 302 at $\mathrm{A}: \mathrm{O}=1: 1$. Then, $99.79 \%$ of $\mathrm{Nd}$ can be recovered with $0.2 \mathrm{~mol} / \mathrm{L} \mathrm{NaCyanex} 302$ in two counter current extraction stages at $\mathrm{A}: \mathrm{O}=1: 1$.

Ion-Pair Solvent Extraction

Ion-pair solvent extraction is effective in the presence of strong anionic ligands because of ion-pair solvent extraction metal ions as anionic complexes. Ion-pair solvent extract mainly nitrogen and oxygen containing organic compounds, such as tri-alkyl methylamine (Primene JMT) and tri-octylmethylammonium nitrate (Aliquat 336).

According to early work, separation factors for adjacent REEs with primary or tertiary amines were higher in sulfate media than in chloride media, so that sulfate media was more promising for ion-pair solvent extraction [113,114]. El-Yamani and Shabana indicated that the extraction of La from sulfate solutions with Primene JMT was extracted according to the following Reactions (4) and (5) [115]. The extraction reaction of quaternary ammonium salts could be also simply represented as Reaction (6) [116,117] where $\mathrm{RNH}_{2}$ denotes the Primene JMT in the organic phase, Ln denotes the rare earth ion and $\mathrm{R}_{4} \mathrm{~N}^{+} \mathrm{NO}_{3}{ }^{-}$the quaternary ammonium nitrate salt.

$$
\begin{gathered}
2 \overline{\mathrm{RNH}_{2}}+\mathrm{H}_{2} \mathrm{SO}_{4}=\overline{\left(\mathrm{RNH}_{3}\right)_{2} \mathrm{SO}_{4}} \\
2 \mathrm{La}\left(\mathrm{SO}_{4}\right)_{2}{ }^{3-}+\overline{3\left(\mathrm{RNH}_{3}\right)_{2} \mathrm{SO}_{4}}=\overline{2\left(\mathrm{RNH}_{3}\right)_{3} \mathrm{La}\left(\mathrm{SO}_{4}\right)_{3}+3 \mathrm{SO}_{4}{ }^{2-}} \\
\mathrm{Ln}^{3+}+3 \mathrm{NO}_{3}{ }^{-}+x \overline{\left(\mathrm{R}_{4} \mathrm{~N}^{+} \mathrm{NO}_{3}{ }^{-}\right.}{ }_{n}=\overline{\mathrm{Ln}\left(\mathrm{NO}_{3}\right)_{3} \mathrm{xnR}_{4} \mathrm{~N}^{+} \mathrm{NO}_{3}{ }^{-}}
\end{gathered}
$$

Amines is mainly used for the separation of $\mathrm{Pr}, \mathrm{Nd}, \mathrm{Y}$ and heavy lanthanoids [117]. Lu et al. [118] obtained a high purity (>99\%) of Nd with recovery of $95 \%$ from didymium nitrate solution by Aliquat 336 in a 45-stage tube-type mixer-settler. Another study described a solvent-extraction process for the recovery of magnet-grade $\mathrm{Nd}_{2} \mathrm{O}_{3}$ from a light rare earth nitrate liquor used a $0.50 \mathrm{~mol} / \mathrm{L}$ Aliquat 336 nitrate in Shellsol AB in 8 extraction and 6 scrubbing stages [119].

Neutral Solvent Extraction

Various neutral extractants have been used for REEs separations, and it has been confirmed that TODGA is a promising extractant [120] and could be used for the extraction of REEs from the NdFeB magnet scrap leaching solution. TODGA forms a strong tridentate complex with metal ions, and, 
compared with other ions in aqueous solution, it has previously exhibited particularly good extraction performance for lanthanides and action elements in terms of the selectivity [121].

The effect of the diluent on the extraction and the selectivity of the TODGA was researched by Gergoric et al. [52]. The efficiency of the diluents decreases in the following order: hexane < cyclohexanone $<$ Solvent $70<$ toluene $<1$-octanol. With the exception of cyclohexanone, the distribution ratio of extractable substances decreases with the polarity of the diluent [122]. It was also found that, in all diluents, the distribution ratio of REEs increased with TODGA concentration increased. A supported liquid membrane processes for extracting REEs from NdFeB magnets with TODGA or Cyanex 923 as extractants were evaluated to define the distribution coefficient and selectivity of $\mathrm{Nd}$ and Dy, respectively. It was found that TODGA has superior selectivity in REEs recovery than Cyanex 923. REEs solution in $\mathrm{HNO}_{3}$ showed higher distribution coefficients and selectivity than in $\mathrm{HCl}$. Lower molar concentration of $\mathrm{HNO}_{3}$ in the strip resulted in higher recovery of $\mathrm{Nd}$ [123].

\section{Synergetic Solvent Extraction}

The phenomenon that the distribution coefficient of some extracted substances is greater than the sum of the partition coefficients when two or more extractants are used alone under the same conditions is called the synergistic effects. Many types of synergistic solvent extraction systems for extracting and separating REEs have been reported, including mixtures of acidic extractants, mixtures of neutral extractants, and combinations thereof [124-127].

In the past ten years, the use of different mixtures of acidic organophosphorous extractants to improve the extraction efficiency and selectivity of REEs has attracted attention. Extraction of REEs with a mixture of D2EHPA and EHEHPA was reported to be a promising method, which could not only decrease the acidity required for stripping the loaded D2EHPA but also increase the extraction efficiency of EHEHPA $[128,129]$. Higher selectivity and extraction efficiency of REEs can be achieved by using mixtures of D2EHPA and EHEHPA. The extraction reaction of REE with cationic extractants D2EHPA and EHEHPA, represented as Reaction (7) [130,131].

$$
\mathrm{REE}^{3+}+\mathrm{mH}_{2} \mathrm{~A}_{2}=\mathrm{REEA}_{3}(\mathrm{HA})_{2 \mathrm{~m}-3}+3 \mathrm{H}^{+}
$$

where $\mathrm{H}_{2} \mathrm{~A}_{2}$ represents the dimeric form of the extractant.

It was suggested that the improvement of the extraction capacity of the mixed system may be attributed to the breakage of the dimers of D2EHPA and EHEHPA [132,133]. As the HCl concentration increases, with the exception of the cationic exchange reaction in Reaction (7), a solvating reaction has been proposed, as shown in Reaction (8) [131].

$$
\mathrm{REE}^{3+}+3 \mathrm{Cl}^{-}+\mathrm{mH}_{2} \mathrm{~A}_{2}=\mathrm{REECl}_{3}(\mathrm{HA})_{2 \mathrm{~m}}
$$

Extraction of $\mathrm{Nd}$, Dy, and $\mathrm{Y}$ from $\mathrm{HCl}$ solution by using D2EHPA, EHEHPA and their mixtures were investigated by Mohammadi et al. [105], the extraction order in general was found to be $\mathrm{Y}>\mathrm{Dy}>$ $\mathrm{Nd}$. The extraction efficiency of $\mathrm{Y}, \mathrm{Dy}$, and Nd increased with the extractant concentration increased and the acidity decreased. Mixture of EHEHPA and D2EHPA improves the extraction of Nd when extractants concentration of $0.15 \mathrm{~mol} / \mathrm{L}$ and equilibrium $\mathrm{pH}=1$. Separation factors calculated for an equilibrium $\mathrm{pH}$ of 1 show that at low concentration of extractant $(0.06 \mathrm{~mol} / \mathrm{L}$ and $0.09 \mathrm{~mol} / \mathrm{L})$ the mixture of EHEHPA and D2EHPA beneficial to separate Dy and Y. The REE distribution ratios and EHEHPA/D2EHPA ratios of the two extractants and their mixtures at different extractant concentrations indicate that the stoichiometrically different complexes of $\mathrm{Dy}, \mathrm{Nd}$ and $\mathrm{Y}$ depend on the concentration of REEs and D2EHPA concentration.

The synergistic extraction of $\mathrm{Nd}$ from $\mathrm{HNO}_{3}$ medium using the mixture of Cyanex 272 and Cyanex 921/Cyanex 923 (B) has been studied by Panda et al. [134]. The extraction of $\mathrm{Nd}$ from $0.001 \mathrm{~mol} / \mathrm{L} \mathrm{HNO}_{3}$ using $0.6 \mathrm{~mol} / \mathrm{L}$ Cyanex 272 in kerosene was $95.5 \%$. It was found that the calculated synergy coefficient 
for the extraction of $\mathrm{Nd}$ using a mixture of $0.1 \mathrm{~mol} / \mathrm{L}$ Cyanex 272 and Cyanex 923 was higher than that for the extraction of a mixture of $0.1 \mathrm{~mol} / \mathrm{L}$ Cyanex 272 and Cyanex 921 in $0.001 \mathrm{~mol} / \mathrm{L} \mathrm{HNO}_{3}$ solution.

To increase the extraction of $\operatorname{Pr}$ and Nd by Cyanex 272, the mixture of Cyanex 272 with Alamine 336, TOA or TEHA have been employed from chloride solution [135]. Among those mixture systems, the Cyanex 272 and Alamine 336 mixture performed the highest synergism enhancement factors for $\operatorname{Pr}(14.2)$ and $\mathrm{Nd}$ (10.1). The extraction reaction of $\mathrm{Pr}$ and $\mathrm{Nd}$ with the mixture of Cyanex 272 and Alamine 336 progresses gradually. At first, the REEs were extracted by Cyanex 272 with a cationic exchange mechanism (Equation (9)). Secondly, during the extraction process, the protons released by Cyanex 272 were simultaneously extracted into organic matter through Alamine336. The overall extraction reaction of Pr and Nd with the mixture of Cyanex 272 and Alamine 336 could be written as Equation (10).

$$
\begin{gathered}
\mathrm{RE}^{3+}+\mathrm{Cl}^{-}+2 \mathrm{H}_{2} \mathrm{~A}_{2}=\mathrm{REClA}_{2} \cdot 2 \mathrm{HA}+2 \mathrm{H}^{+}(\mathrm{RE}=\mathrm{Pr}, \mathrm{Nd}) \\
\mathrm{RE}^{3+}+(\mathrm{x}+1) \mathrm{Cl}^{-}+2 \mathrm{H}_{2} \mathrm{~A}_{2}+\mathrm{xNR}_{3}=\mathrm{RECl}\left(\mathrm{HA}_{2}\right)_{2}+x \mathrm{xR}_{3} \mathrm{NHCl}+(2-\mathrm{x}) \mathrm{H}^{+}(\mathrm{RE}=\mathrm{Pr}, \mathrm{Nd})
\end{gathered}
$$

where the value of $x(0 \leq x \leq 2)$ is dependent on the concentration ratio of Alamine 336 to the chloride ion.

Hence, it can be concluded that the chloride ion concentration in the aqueous phase is significantly affecting the extraction of $\mathrm{Nd}$ and $\mathrm{Pr}$ in the mixture of Cyanex 272 and Alamine 336.

A similar experiment was performed on the extraction of $\mathrm{Nd}$ with a mixture of Cyanex 302 (HB) and Alamine 308 by Kumar et al. The mixture showed a significant synergistic effect with a synergistic factor of 44.1. Raction for extracting Nd with this mixture is shows in Equation (11) [136].

$$
\mathrm{Nd}^{3+}+\mathrm{Cl}^{-}+(\mathrm{HB})_{2}+2 \mathrm{R}_{3} \mathrm{~N}=\mathrm{NdClB}_{2} \cdot 2 \mathrm{R}_{3} \mathrm{~N}+2 \mathrm{H}^{+}
$$

Because of the extractants used in synergistic systems are generally consist of a mixture of acidic and neutral extractant, the acids released during the extraction of REEs with these acidic extractants can adversely affect extraction. Thus, a present work was directed to study the extraction behavior of $\mathrm{La}$ and $\mathrm{Nd}$ from $\mathrm{HNO}_{3}$ solution using a mixture of TOPO and TRPO neutral extractants in kerosene to keep the best conditions to recover and separate REEs. Extraction of $\mathrm{Y}$ from $\mathrm{HNO}_{3}$ medium with a mixture of neutral organophosphorus reagents gave synergistic behavior and forming a neutral complex of the form of $\overline{M\left(\mathrm{NO}_{3}\right)_{3}(\mathrm{TOPO})(\mathrm{TRPO})}$, and the reaction in case of synergism could be written as Equation (12) [137]. The extraction order for the REEs studied was $\mathrm{Nd}>\mathrm{Y}>\mathrm{La}$.

$$
\mathrm{M}^{3+}+3 \mathrm{NO}_{3}{ }^{-}+\overline{\mathrm{TOPO}}+\overline{\mathrm{TRPO}}=\overline{\mathrm{M}\left(\mathrm{NO}_{3}\right)_{3}(\mathrm{TOPO})(\mathrm{TRPO})}
$$

\subsubsection{Ionic Liquids Extraction Process}

Ionic liquids (ILs) have the ability to solvate many compounds [138]. Meanwhile, ILs was considered to be environment friendly solvents with the potential to replace traditional organic solvent [139]. Recently, emphasis has been placed on such solvents in cleaner production processes $[140,141]$.

Non-Functional Ionic Liquids

ILs made with imidazolium salts, which are denoted as $\left[C_{n} \mathrm{mim}\right]$, were the first potential ILs to be used for extracting REEs. $\left[\mathrm{C}_{8}\right.$ mim] $\left[\mathrm{PF}_{6}\right]$ was first tested for separating Ce (IV) from $\mathrm{HNO}_{3}$ solutions containing La (III) and Th (IV) [142]. It was found that the distribution ratios of Ce (IV) and Th (IV) using pure $\left[\mathrm{C}_{8} \mathrm{mim}\right]\left[\mathrm{PF}_{6}\right]$ as the extract phase was similar to that using HDEHP or DEHPA in $\mathrm{n}$-heptane, which indicated that $\left[\mathrm{C}_{8} \mathrm{mim}\right]\left[\mathrm{PF}_{6}\right]$ is possible to act as both extractant and diluent.

In traditional organic solvents, metal ions are always extracted with a neutral extractant together with their counter anions, which is called the neutral mechanism. However, the cation exchange mechanism, an anion exchange mechanism, or neutral mechanism can appear in the IL system. 
A general equation of the cation exchange mechanism can be written as in Equation (13) or demonstrated as in Figure 16a, where $\mathrm{L}$ is the extractant, $\mathrm{M}$ is the REE, and $\mathrm{C}$ is the cation of IL.

$$
\mathrm{M}^{\mathrm{m}+}+\mathrm{mL}+\mathrm{mC}_{\mathrm{IL}}^{+}=\mathrm{ML}_{\mathrm{m}, \mathrm{IL}}{ }^{\mathrm{m}+}+\mathrm{mC}^{+}
$$
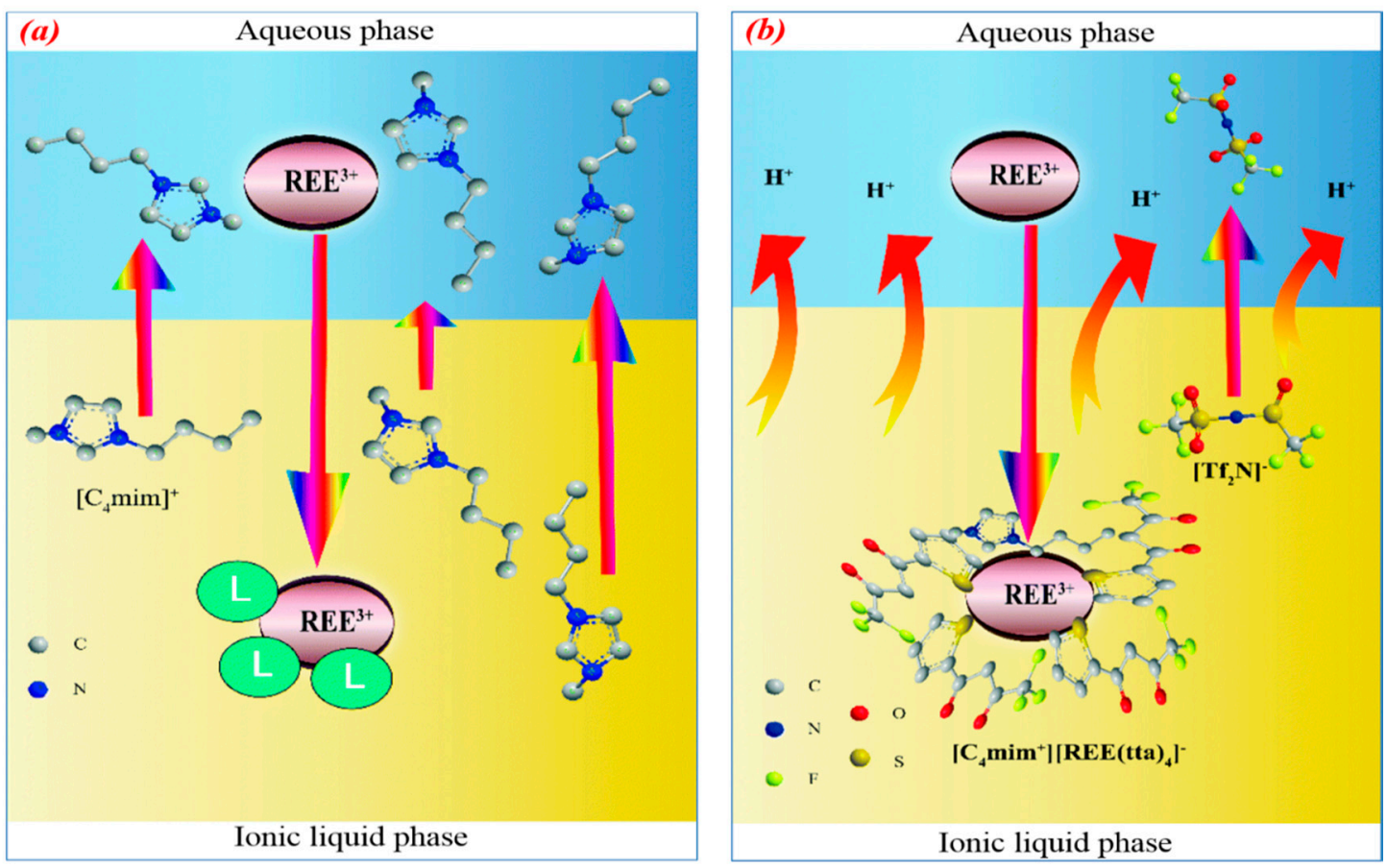

Figure 16. (a) Cation exchange in an ionic liquids (IL) system, (b) Anion exchange in IL system [143]; published by Royal Society of Chemistry, 2017.

The cation exchange mechanism largely depends on the hydrophobic character of ILs, $\mathrm{Nd}^{3+}$ extraction with Cyanex 923 in five ILs with the same anion but different cations showed that the extraction efficiency of $\mathrm{Nd}^{3+}$ in ILs with a small hydrophilic cation such as $\left[\mathrm{C}_{4} \mathrm{mim}\right]\left[\mathrm{Tf}_{2} \mathrm{~N}\right]$ and $\left[\mathrm{N}_{1444}\right]\left[\mathrm{Tf}_{2} \mathrm{~N}\right]$ was higher than that in ILs with a hydrophobic cation such as $\left[\mathrm{C}_{10} \operatorname{mim}\right]\left[\mathrm{Tf}_{2} \mathrm{~N}\right]$, $\left[\mathrm{P}_{66614}\right]\left[\mathrm{Tf}_{2} \mathrm{~N}\right]$, or $\left[\mathrm{N}_{1888}\right]\left[\mathrm{Tf}_{2} \mathrm{~N}\right]$ [144]. In other words, hydrophilic cations promote cation exchange, while hydrophobic cations inhibit cation exchange.

Anion exchange was observed in the biphasic aqueous/IL system by Jensen et al. $\left[\mathrm{C}_{4} \mathrm{mim}\right]\left[\mathrm{Tf}_{2} \mathrm{~N}\right]$ functioned via liquid anion exchange mechanisms accelerates the formation of REE(tta) ${ }_{4}{ }^{-}$in the IL phase, while $\operatorname{REE}(\mathrm{tta})_{3}$ were generally formed in organic solvents or cationic complexes, $\operatorname{REE}(\mathrm{tta})_{2}{ }^{+}$, as observed in previously reported IL systems. $\left[\mathrm{Tf}_{2} \mathrm{~N}\right]^{-}$was transferred to the aqueous phase to keep the charge neutrality, and $\left[\mathrm{C}_{4} \mathrm{mim}^{+}\right]\left[\operatorname{REE}(\mathrm{tta})_{4}^{-}\right]$be part of the IL phase without greatly changing the general structure of the IL [145]. The full equilibrium could be described as in Equation (14), and the details of an anion exchange mechanism in an IL, as shown in Figure 16b.

$$
\mathrm{REE}^{3+}+4 \mathrm{Htta}+\left[\mathrm{C}_{4} \mathrm{mim}\right]\left[\mathrm{Tf}_{2} \mathrm{~N}\right]_{\mathrm{IL}}=\left[\mathrm{C}_{4} \mathrm{mim}+\right]\left[\operatorname{REE}(\mathrm{tta})_{4}{ }^{-}\right]_{\mathrm{IL}}+4 \mathrm{H}^{+}+\left[\mathrm{Tf}_{2} \mathrm{~N}\right]^{-}
$$

Part of the ionic liquid components in the anion exchange system will still be transferred to the water phase, which will contaminate the water phase and consume IL. Therefore, the neutral mechanism opposite to the conventional organic solvent mechanism can also be used in the IL system. According to Kubota et al. [146] the mechanism in $\left[\mathrm{C}_{n}\right.$ mim] $\left[\mathrm{Tf}_{2} \mathrm{~N}\right] / \mathrm{DODGAA}$ is the same as that in 
$\mathrm{n}$-dodecane, that is, protons exchange in the reaction between DODGAA and REEs. The extraction equation of REE $^{3+}$ ions with DODGAA (HL) is given in Equation (15) and Figure 17.

$$
\mathrm{M}^{3+}+3 \mathrm{HL}_{\mathrm{IL}}=\mathrm{ML}_{3, \mathrm{IL}}+3 \mathrm{H}^{+}
$$
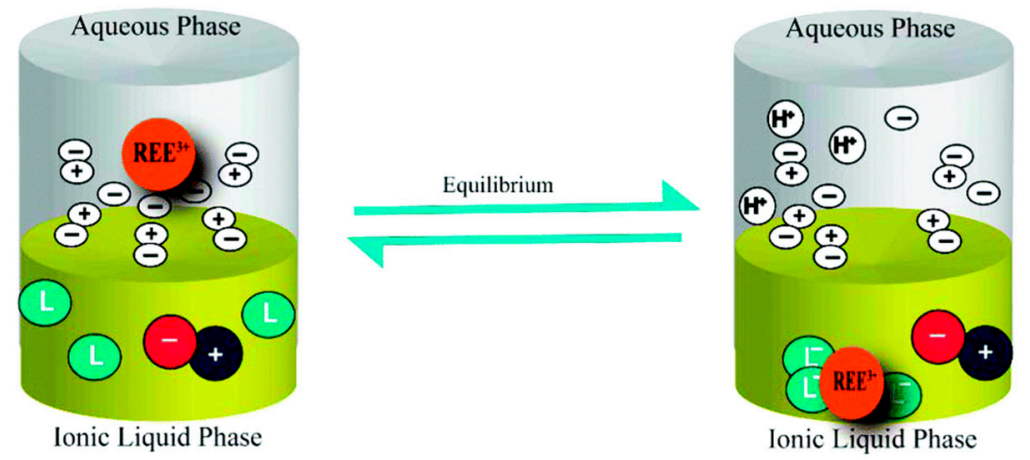

Figure 17. Neutral mechanism in non-functional IL-based extraction system [143]; published by Royal Society of Chemistry, 2017.

The same group used mainly $\left[\mathrm{C}_{8} \mathrm{mim}\right]\left[\mathrm{Tf}_{2} \mathrm{~N}\right]$ with DODGAA as the extractant for extraction of a series of REEs, the results showed that all the REEs can be extracted at low $\mathrm{pH}$ from a $\mathrm{H}_{2} \mathrm{SO}_{4}$ solution. The ILs were confirmed to be applicable for the separation of REEs from a variety of resources [147]. Finally, they used $\left[\mathrm{C}_{4} \mathrm{mim}\right]\left[\mathrm{Tf}_{2} \mathrm{~N}\right] / \mathrm{DODGAA}$ to recover REEs from waste fluorescent lamps, the $\left[\mathrm{C}_{4} \mathrm{mim}\right]\left[\mathrm{Tf}_{2} \mathrm{~N}\right] / \mathrm{DODGAA}$ showed a high affinity for REEs in liquid-liquid extraction [148]. $\left[\mathrm{C}_{4} \mathrm{mim}\right]\left[\mathrm{Tf}_{2} \mathrm{~N}\right] / \mathrm{DODGAA}$ showed to be a promising system for recovering REEs from fluorescent lamps or NdFeB magnets containing large amounts of $\mathrm{Zn}$ and Fe.

Functional Ionic Liquids

Since one of the most important characteristics of IL is to improve its chemical and physical properties by combining appropriate anion/cation pairs, functional groups can be introduced into anionic or cationic compositions. IL with functional groups is called functional IL, and due to its unique chemical and physical properties, it has attracted much attention in the metal recycling process [149-152].

The ionic liquids $\left[\mathrm{C}_{6} \mathrm{mim}\right][\mathrm{DEHP}], \quad\left[\mathrm{C}_{6} \mathrm{mpyr}\right][\mathrm{DEHP}]$ and $\left[\mathrm{N}_{4444}\right][\mathrm{DEHP}]$ with bis(2-ethylhexyl)phosphate anions were prepared and the extraction behavior of $\mathrm{Nd}$ with the ILs extraction in $\mathrm{HNO}_{3}$ medium were studied. Compared with the quaternary ammonium analog [ $\left.\mathrm{N}_{4444}\right][\mathrm{DEHP}]$, except the extraction properties of $\mathrm{Nd}$ in the ionic liquids $\left[\mathrm{C}_{6} \mathrm{mim}\right][\mathrm{DEHP}]$ and $\left[\mathrm{C}_{6}\right.$ mpyr][DEHP] were significantly different, the extraction efficiency of $\mathrm{Nd}$ can exceed $99 \%$, and the extraction process can be selected by the ionic liquid cation [148]. In another research, because the functional phosphate moiety of DEHPA, $\mathrm{Nd}^{3+}$ was extracted by $\left[\mathrm{C}_{6} \mathrm{mim}\right]\left[\mathrm{Tf}_{2} \mathrm{~N}\right] / \mathrm{DEHPA}$ and $\left[\mathrm{C}_{6} \mathrm{mpyr}\right]\left[\mathrm{Tf}_{2} \mathrm{~N}\right] / \mathrm{DEHPA}$ systems, the Equation (16) can be proposed for the extraction mechanism of $\mathrm{Nd}$ by DEHPA in $\left[\mathrm{C}_{6} \mathrm{mim}\right]\left[\mathrm{NTf}_{2}\right]$ and $\left[\mathrm{C}_{6} \mathrm{mpyr}\right]\left[\mathrm{NTf}_{2}\right]$ [153]. These non-functional ILs only acted as dilutants and were not included in the extraction mechanism, as shown in Figure 18. When the functional IL $\left[\mathrm{C}_{6} \mathrm{mim}\right][\mathrm{DEHP}]$ was used to extract $\mathrm{Nd}^{3+}$, both the anion and cation were involved in the extraction so that neither cation nor anion was lost to the aqueous phase.

$$
\mathrm{Nd}^{3+}+\overline{3 D E H P A}=\overline{\mathrm{Nd}(D E H P)_{3}}+3 H^{+}
$$




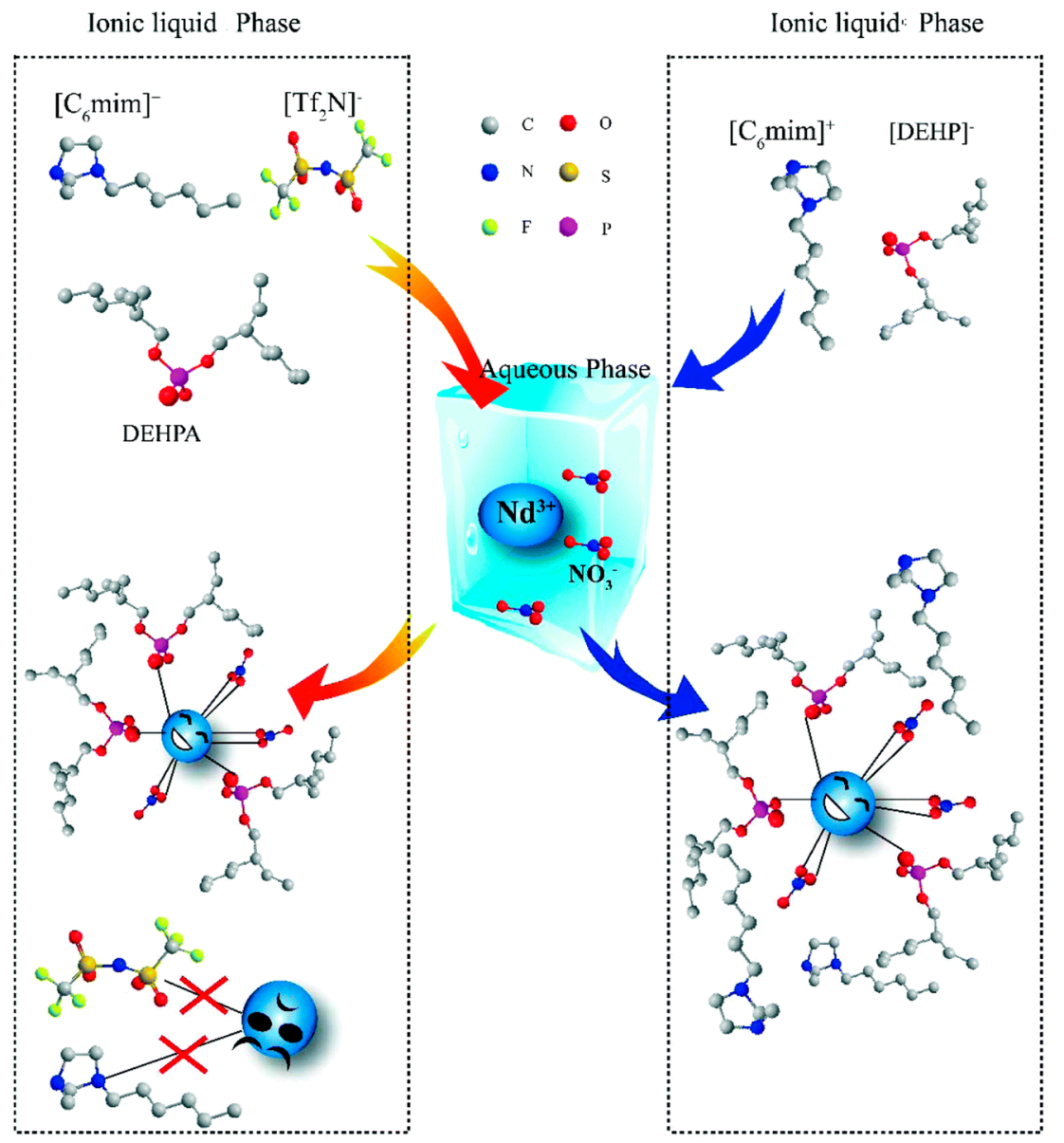

Figure 18. Different $\mathrm{Nd}^{3+}$ extraction behaviors in $\left[\mathrm{C}_{6} \mathrm{mpyr}\right]\left[\mathrm{Tf}_{2} \mathrm{~N}\right] / \mathrm{DEHPA}$ and $\left[\mathrm{C}_{6} \mathrm{mim}\right][\mathrm{DEHP}]$ systems [143]; published by Royal Society of Chemistry, 2017.

The use of these type of functionalized ionic liquids for separating REEs indicated that the light REEs La and $\mathrm{Ce}$ are poorly extracted, however, $\mathrm{Nd}$ and $\mathrm{Yb}$ are strongly extracted by the $\left[\mathrm{C}_{6} \mathrm{mim}\right][\mathrm{DEHP}] /\left[\mathrm{C}_{6} \mathrm{mim}\right]\left[\mathrm{NTf}_{2}\right]$ and $\left[\mathrm{C}_{6} \mathrm{mpyr}\right][\mathrm{DEHP}] /\left[\mathrm{C}_{6} \mathrm{mpyr}\right]\left[\mathrm{NTf}_{2}\right]$ ionic liquid extraction systems. A separation factor of 340 is obtained for $\mathrm{Nd}$ over $\mathrm{La}$ in the $\left[\mathrm{C}_{6} \mathrm{mim}\right][\mathrm{DEHP}]$. Pr is weakly extracted by the $\left[\mathrm{C}_{6} \mathrm{mpyr}\right][\mathrm{DEHP}] /\left[\mathrm{C}_{6} \mathrm{mpyr}\right]\left[\mathrm{NTf}_{2}\right]$ system, but rather strongly by the $\left[\mathrm{C}_{6} \mathrm{mim}\right][\mathrm{DEHP}] /\left[\mathrm{C}_{6} \mathrm{mim}\right]\left[\mathrm{NTf}_{2}\right]$ system. Overall, these DEHPA-based ILs were suitable for recovering $\mathrm{Nd}$ from $\mathrm{NdFeB}$ magnet scrap.

A new recycling process for NdFeB magnets was carried out by Dupont and Binnemans, based on the carboxyl-functionalized ionic liquid: betainium bis(trifluoromethylsulfonyl)imide, [Hbet][Tf $\left.{ }_{2} \mathrm{~N}\right]$, a combined leaching/extraction step was proposed, and the detailed recycling process as shown in Figure 19 [36]. First, roasting of $\mathrm{NdFeB}$ magnets convert all elements in the magnets to their respective oxides, because these oxides are more easily dissolved in $[\mathrm{Hbet}]\left[\mathrm{Tf} \mathrm{f}_{2} \mathrm{~N}\right]-\mathrm{H}_{2} \mathrm{O}$ systems. The leaching of the roasted $\mathrm{NdFeB}$ was tested using a $1: 1 \mathrm{wt} / \mathrm{wt}[\mathrm{Hbet}]\left[\mathrm{Tf}_{2} \mathrm{~N}\right]-\mathrm{H}_{2} \mathrm{O}$ at $80^{\circ} \mathrm{C}$ to form a homogeneous phase. After that, the solution was cooled to $25^{\circ} \mathrm{C}$, the mixture could be separated into a valuable REEs/Co-rich aqueous phase and an iron-rich ionic liquid phase. The two separated phases were stripped with $\mathrm{H}_{2} \mathrm{C}_{2} \mathrm{O}_{4}$ to remove the $\mathrm{Fe}$ and produce a REEs/Co oxalate. Then, aqueous ammonia was added to separate REEs and Co. The obtained REEs oxalate with a purity higher than $99.9 \%$ and can be calcined to obtain $\mathrm{Nd}_{2} \mathrm{O}_{3}$ and $\mathrm{Dy}_{2} \mathrm{O}_{3}$ mixture, which is the precursors of $\mathrm{NdFeB}$ magnets. The stripping step can automatically regenerate the ionic liquid, and the ionic liquid recovery was also considered. Therefore, the proposed closed-loop system only generates little waste and offers selectivity, which makes this a promising green method for recovering NdFeB magnets [149]. 


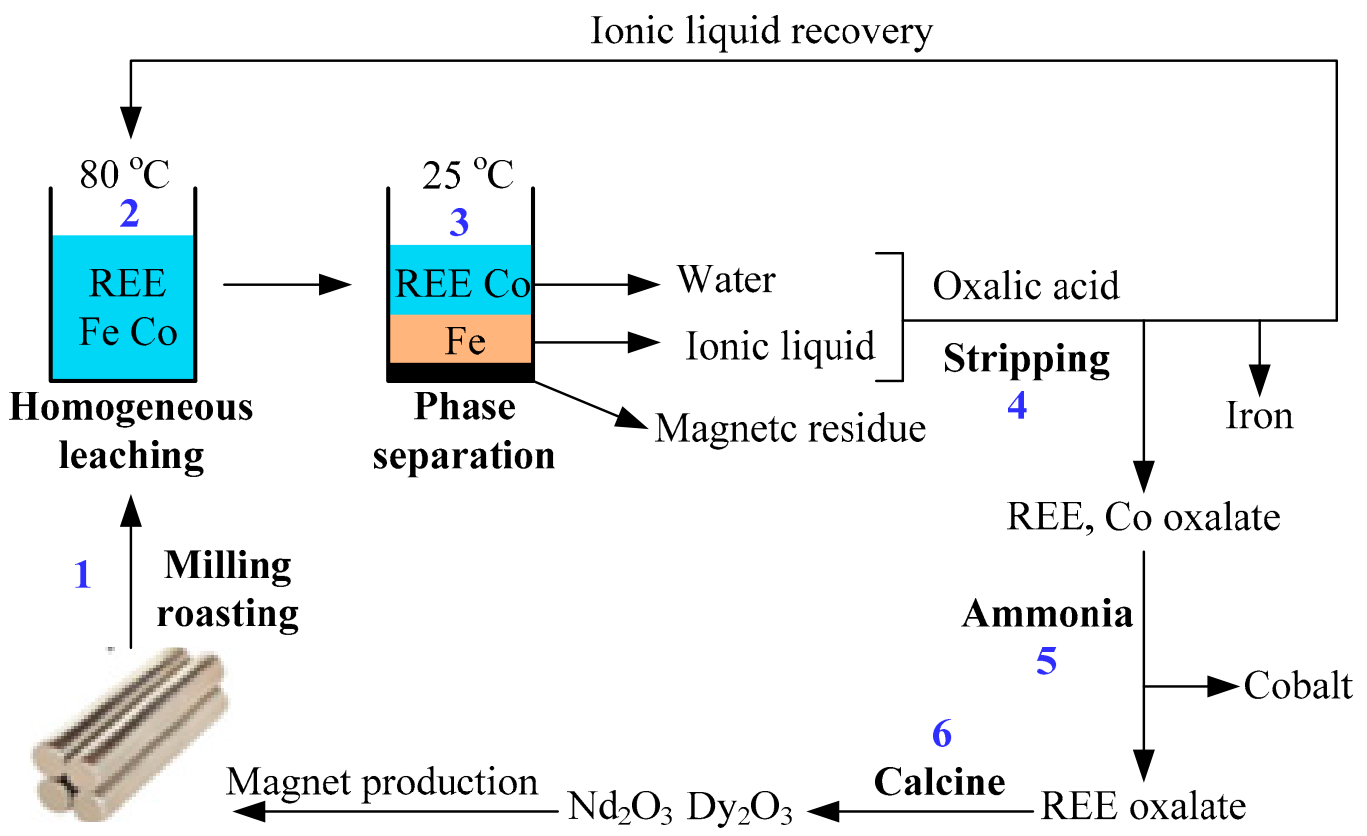

Figure 19. Overview of the proposed recycling process for roasted NdFeB magnets [36]; published by Royal Society of Chemistry, 2015.

Bi-Functional Ionic Liquids

Ionic liquid extractants prepared from ammoniumand phosphonium are considered to be bi-functional IL extractants (Bif-ILs) because the cations and anions of ILs are involved in the extraction [150].

Rout et al. [148] synthesized two ionic liquids derived from Aliquat 336: trioctylmethylammonium bis(2-ethylhexyl)phosphate, [A336][DEHP], and trioctylmethylammonium bis(2-ethylhexyl)diglycolamate, [A336][DGA]. These ionic liquids were applied to the separation of $\mathrm{Eu}$ from Am. The extraction of Eu in these Bif-ILs showed a strong dependence on the properties of molecular diluent used. In their further researcher [151], [A336][DGA] combined with [A336][ $\mathrm{NO}_{3}$ ] to extract $\mathrm{Nd}$ from La ions, and the $\mathrm{Nd}$ extraction behavior of [A336][DGA] in [A336][ $\mathrm{NO}_{3}$ ] was compared with that of [A336][DGA] in the Cl-containing ionic liquid diluent [A336][Cl]. The results shown that extraction of $\mathrm{Nd}$ can reach nearly $100 \%$, and the nitrate media was found to be more suitable for extracting $\mathrm{Nd}$ than in chloride media. The extraction mechanism in a system with the ionic liquid diluent [A336] $\left[\mathrm{NO}_{3}\right]$ is significant different from that of extraction systems with molecular diluents. A rational mechanism for extracting $\mathrm{Nd}$ by [A336][DGA] in [A336][ $\mathrm{NO}_{3}$ ] at $\mathrm{pH} 2-5$ with $0.1 \mathrm{M}$ salting-out agent in the feed phase is shown as Equation (17).

$$
\mathrm{Nd}^{3+}+3 \mathrm{NO}_{3}^{-}+\overline{[A 336][D G A]}=\overline{\mathrm{Nd}\left(\mathrm{NO}_{3}\right)_{3} \bullet[A 336][D G A]}
$$

A comparative study was carried out between Bi-ILs [A336][CA-12] (tricaprylmethylammonium secoctylphenoxy acetic acid)/[A336][CA-100] (tricaprylmethylammonium secnonylphenoxy acetic acid), organic carboxylic acids CA-12/CA-100 and neutral organophosphorus extractants TBP/P350 for extracting REEs in $\mathrm{HNO}_{3}$ medium [148]. The efficiency of different extractants for metal extraction follows the order: [A336][CA-12]/[A336][CA-100] > CA-12/CA-100 > TBP/P350. Extraction and separation for REEs from chloride medium used [A336][CA-12] and [A336][CA-100] as extractants have also researched by Wang et al. [152] The results showed that at the same conditions, the extraction capacity of [A336][CA-12] and [A336][CA-100] was higher than that of CA-12, CA-100, TBP, and P350. [A336][CA-12] and [A336][CA-100] in the present of $\mathrm{NaCl}$, can efficiently extraction of REEs at 
low acidity, avoiding the harm that the conventional acidity and neutral extractants produced in the extraction.

The inner synergistic effect of Bi-ILs extractants using [A336][P204] as an extractant for solvent extraction of Eu was reported. The distribution coefficients of Eu in [A336][P204], [A336][P507], [A336][CA-12], [A336][CA-100], [A336][Cyanex272] and corresponding mixtures of their precursors were carried out to explore whether there are similar inner synergistic effects in some other Bi-ILs [153]. As shown in Table 6, obviously, the distribution coefficients of the Bi-ILs are all higher than their mixed precursors, showing good inner synergistic effect of these Bi-ILs [154]. HDEHP and HEH [EHP] have been developed into 6 types acid-base coupling bifunctionalized ionic liquids (ABC-BILs) extractants. As with the mixture of HDEHP and HEH[EHP], the combined [DEHP]2 type ABC-BILs and [EHEHP]2 type ABC-BILs revealed synergistic extraction effects for REEs in 7 different ABC-BILs combinations. The synergy coefficients of REEs also confirmed the synergistic extraction effects from combined ABC-BILs [155].

Table 6. Comparison of the distribution ratios obtained using mixed extractants and Bi-ILs in hydrochloric acid and nitric acid media [154]; published by Elsevier, 2010.

\begin{tabular}{ccccc}
\hline \multirow{2}{*}{ Extractant } & \multicolumn{2}{c}{ Hydrochloric Acid Media } & \multicolumn{2}{c}{ Nitric Acid Media } \\
\cline { 2 - 5 } & $\mathbf{D}$ & $\mathbf{D}_{\text {IL }} / \mathbf{D}_{\text {mix }}$ & $\mathbf{D}$ & $\mathbf{D}_{\text {IL }} / \mathbf{D}_{\text {mix }}$ \\
\hline A336 + P204 & 0.071 & 27.86 & 0.912 & 23.79 \\
\hline$[$ A336][P204] & 1.97 & - & 21.7 & - \\
\hline A336 + P507 & 0.192 & 13.28 & 0.269 & 70.63 \\
\hline$[$ A336][P507] & 2.55 & - & 19 & - \\
\hline A336 + CA-12 & 0.169 & 3.04 & 0.067 & 19.79 \\
\hline$[$ A336][CA-12] & 0.513 & - & 1.33 & - \\
\hline A336+ CA-100 & 0.054 & 8.28 & 0.055 & 15.57 \\
\hline$[$ A336][CA-100] & 0.445 & - & 0.855 & - \\
\hline A336 + Cyanex272 & 0.928 & 2.55 & 0.912 & 3.44 \\
\hline$[$ A336][Cyanex272] & 2.37 & - & 3.14 & - \\
\hline
\end{tabular}

It was indicated that the IL consisting the mixture of Aliquat 336 and Cyanex 272 showed good selectivity and extractability for REEs, therefore, a detailed study has been researched to extract $\mathrm{Nd}$ and $\mathrm{Pr}$ using Aliquat 336 based ionic liquid from the NdBFe magnet scrap leach liquor. A comparative study showed that the extraction efficiency of Bi-ILs trioctylmethylammoniumbis (2,4,4-trimethylpentyl)phosphate $\left(\mathrm{R}_{4} \mathrm{NCy}\right)$ and trioctylmethylammonium di(2-ethylhexyl)phosphate $\left(\mathrm{R}_{4} \mathrm{ND}\right)$ was higher than the conventional extractants Aliquat 336, Cyanex 272 and D2EHPA under the same conditions. The extraction efficiency of different extractants for $\mathrm{Nd}$ and $\mathrm{Pr}$ is: $\mathrm{R}_{4} \mathrm{NCy}>$ $\mathrm{R}_{4} \mathrm{ND}>$ Cyanex $272>\mathrm{D} 2 \mathrm{EHPA}>$ Aliquat 336, with a maximum extraction of $\mathrm{Nd}$ and $\mathrm{Pr}$ of $98.97 \%$, $99.02 \%$, respectively.

\section{Conclusions}

NdFeB permanent magnet scrap is an important secondary resource that contains a number of valuable REEs. Recovery of REEs from this scrap via appropriate methods such as hydrometallurgical processes has both remarkable economic and environmental benefits. The authors reviewed the chemical, physical characteristics of $\mathrm{NdFeB}$ permanent magnet scrap and the main hydrometallurgical processes for recovering REEs from the magnet scrap, from the leaching process to the separation process. A variety of leaching technologies have been developed for REEs recovery depending upon their mineralogy, REEs occurrence and engineering feasibility. Both selective leaching and complete leaching are interactively used for leaching REEs from the magnet scrap, among which 
complete leaching treatment was found to be acceptable from industrial point of view. Although electrochemical selectively leaching seems to be a promising method, more systematic research is still needed. The REEs separation process mainly include precipitation process, solvent extraction process and ionic liquids extraction process. The precipitation process is a simple and easy separation process for REEs by different precipitating reagents; however, the problem of incomplete separation needs to be addressed. The leaching liquor generated is put to solvent extraction studies using different process such as acidic solvent extraction, ion-pair solvent extraction, neutral solvent extraction and synergetic solvent extraction. D2EHPA and PC88A have been considered feasible for recovering REEs from the leaching liquors. The physical properties of ionic liquids make them potentially valuable replacements for traditional organic solvents used in liquid-liquid separation processes. However, the extraction mechanisms of ionic liquids extraction are still indefinite, and the high price of most types of ionic liquids hinders its widespread use. Future research focus should be on the understanding of extraction mechanisms, which is very important for the better design of extraction systems from laboratory curiosities to industrial processes. Technically, for further optimization of treatment of the magnet scrap, hydrometallurgical recovery of REEs from the magnet scrap has to confront the challenges of many process steps required before obtaining REEs, consumption of large amount of chemicals, generation of large amount waste water and effluents. To resolve these issues, it is necessary to use high selective leaching agents, recycle the leaching agents and establish a closed-loop system. This review is expected to serve as a useful guideline for promoting treatment of NdFeB permanent magnet scrap by a hydrometallurgical processes.

Author Contributions: Conceptualization: Y.Z.; Investigation: F.G.; Data Curation: Z.S.; Formal analysis: S.L.; Writing-original draft preparation: F.G.; Writing—review and editing: Y.Z. and C.A.; Supervision: T.J. All authors have read and agreed to the published version of the manuscript.

Funding: This research was funded by the National Natural Science Foundation of China under Grant U1960114.

Conflicts of Interest: The authors declare no conflict of interest.

\section{References}

1. Jiles, D. Introduction to Magnetism and Magnetic Materials, 2nd ed.; Chapman \& Hall: New York, NY, USA, 1998.

2. Coey, J.M.D. Permanent magnet applications. J. Magn. Magn. Mater. 2002, 248, 441-456. [CrossRef]

3. Shaw, S.; Constantinides, S. Permanent magnets: The demand for rare earths. In Proceedings of the 8th International Rare Earths Conference, Hong Kong, China, 13-15 November 2012.

4. Yang, Y.; Walton, A.; Sheridan, R.; Güth, K.; Gauß, R.; Gutfleisch, O.; Buchert, M.; Steenari, B.-M.; Van Gerven, T.; Jones, P.T.; et al. REE Recovery from end-of-life NdFeB permanent magnet scrap: A critical review. J. Sustain. Metall. 2016, 3, 122-149. [CrossRef]

5. Sagawa, M.; Fujimura, S.; Yamamoto, H.; Matsuura, Y.; Hiraga, K. Permanent magnet materials based on the rare earth-iron-boron tetragonal compounds. IEEE Trans. Magn. 1984, 20, 1584-1589. [CrossRef]

6. Peiró, L.T.; Méndez, G.V.; Ayres, R.U. Material flow analysis of scarce metals: Sources, functions, end-uses and aspects for future supply. Environ. Sci. Technol. 2013, 47, 2939-2947. [CrossRef] [PubMed]

7. Japan Oil Gas and Metals National Corporation. Mineral Resources Material Flow; Japan Oil Gas and Metals National Corporation: Tokyo, Japan, 2008. Available online: mric.jogmec.go.jp/public/report/2012-12/ 2012120122_REs.pdf (accessed on 29 May 2020).

8. Mochizuki, Y.; Tsubouchi, N.; Sugawara, K. Selective recycling of rare earth elements from Dy containing NdFeB magnets by chlorination. ACS Sustain. Chem. Eng. 2013, 1, 655-662. [CrossRef]

9. Zakotnik, M.; Tudor, C.O.; Peiró, L.T.; Afiuny, P.; Skomski, R.; Hatch, G.P. Analysis of energy usage in $\mathrm{Nd}-\mathrm{Fe}-\mathrm{B}$ magnet to magnet recycling. Environ. Technol. Inno. 2016, 5, 117-126. [CrossRef]

10. Lee, K.; Yoo, K.; Yoon, H.-S.; Kim, C.J.; Chung, K.W. Demagnetization followed by remagnetization of waste NdFeB magnet for reuse. Geosyst. Eng. 2013, 16, 286-288. [CrossRef]

11. Sheridan, R.S.; Williams, A.J.; Harris, I.R.; Walton, A. Improved HDDR processing route for production of anisotropic powder from sintered NdFeB type magnets. J. Magn. Magn. Mater. 2014, 350, 114-118. [CrossRef] 
12. Gutfleisch, O.; Güth, K.; Woodcock, T.G.; Schultz, L. Recycling used Nd-Fe-B sintered magnets via a hydrogen-based route to produce anisotropic, resin bonded magnets. Adv. Energy Mater. 2013, 3, $151-155$. [CrossRef]

13. Itoh, M.; Masuda, M.; Suzuki, S.; Machida, K.-I. Recycling of rare earth sintered magnets as isotropic bonded magnets by melt-spinning. J. Alloy. Compd. 2004, 374, 393-396. [CrossRef]

14. Li, C.; Liu, W.Q.; Yue, M.; Liu, Y.Q.; Zhang, D.T.; Zuo, T.Y. Waste Nd-Fe-B sintered magnet recycling by doping with rare earth rich alloys. IEEE Trans. Magn. 2014, 50, 2015403. [CrossRef]

15. Hogberg, S.; Holboll, J.; Mijatovic, N.; Jensen, B.B.; Bendixen, F.B. Direct reuse of rare earth permanent magnets-coating integrity. IEEE Trans. Magn. 2017, 53, 1-9. [CrossRef]

16. Xia, M.; Abrahamsen, A.B.; Bahl, C.R.H.; Veluri, B.; Søegaard, A.I.; Bøjsøe, P. Hydrogen decrepitation press-less process recycling of ndfeb sintered magnets. J. Magn. Magn. Mater. 2017, 441, 55-61. [CrossRef]

17. Sheridan, R.S.; Sillitoe, R.; Zakotnik, M. Anisotropic powder from sintered NdFeB magnets by the HDDR processing route. J. Magn. Magn. Mater. 2012, 324, 63-67. [CrossRef]

18. Zakotnik, M.; Harris, I.R.; Williams, A.J. Possible methods of recycling NdFeB-type sintered magnets using the HD/degassing process. J. Alloy. Compd. 2008, 450, 525-531. [CrossRef]

19. Bian, Y.Y.; Guo, S.; Tang, K.; Jiang, L.; Lu, C.; Lu, X.; Ding, W. Recovery of rare earth elements from permanent magnet scraps by pyrometallurgical process. Rare Met. 2015. [CrossRef]

20. Hua, Z.; Wang, L.; Wang, J.; Xiao, Y.; Yang, Y.; Zhao, Z.; Liu, M. Extraction of rare earth elements from NdFeB scrap by $\mathrm{AlF}_{3}-\mathrm{NaF}$ melts. Mater. Sci. Tech. 2014, 31, 1007-1010. [CrossRef]

21. Hua, Z.; Wang, J.; Wang, L.; Zhao, Z.; Li, X.; Xiao, Y.; Yang, Y. Selective extraction of rare earth elements from NdFeB scrap by molten chlorides. ACS Sustain. Chem. Eng. 2014, 2, 2536-2543. [CrossRef]

22. Saito, T.; Sato, H.; Ozawa, S.; Yu, J.; Motegi, T. The extraction of Nd from waste Nd-Fe-B alloys by the glass slag method. J. Alloy. Compd. 2003, 353, 189-193. [CrossRef]

23. Takeda, O.; Okabe, T.H.; Umetsu, Y. Phase equilibrium of the system Ag-Fe-Nd, and Nd extraction from magnet scraps using molten silver. J. Alloy. Compd. 2004, 379, 305-313. [CrossRef]

24. Moore, M.; Gebert, A.; Stoica, M. A route for recycling Nd from Nd-Fe-B magnets using Cu melts. J. Alloy. Compd. 2015, 647, 997-1006. [CrossRef]

25. Bian, Y.; Guo, S.; Jiang, L.; Liu, J.; Tang, K.; Ding, W. Recycling of rare earth elements from NdFeB magnet by VIM-HMS method. ACS Sustain. Chem. Eng. 2016, 4, 810-818. [CrossRef]

26. Bian, Y.; Tang, K.; Gabriella, R. A thermodynamic assessment of the Nd-C system. Calphad 2015, 51, $206-210$. [CrossRef]

27. Miura, K.; Itoh, M.; Machida, K.I. Extraction and Recycling Characteristics of Fe element from Nd-Fe-B sintered magnet powder scrap by carbonylation. J. Alloy. Compd. 2008, 466, 228-232. [CrossRef]

28. Firdaus, M.; Rhamdhani, M.A.; Durandet, Y.; Rankin, W.J.; McGregor, K. Review of high-temperature recycling of rare earth (Nd/Dy) from magnet waste. J. Sustain. Metall. 2016, 2, 276-295. [CrossRef]

29. Uda, T. Recycling of rare earths from magnet sludge by $\mathrm{FeCl}_{2}$. Mater. Trans. 2002, 43, 55-62. [CrossRef]

30. Itoh, M.; Miura, K.; Machida, K.I. Novel rare earth recycling process on Nd-Fe-B magnet scrap by selective chlorination using $\mathrm{NH}_{4} \mathrm{Cl}$. J. Alloy. Compd. 2009, 477, 484-487. [CrossRef]

31. Yamada, E.; Murakami, H.; Nishihama, S.; Yoshizuka, K. Separation process of dysprosium and neodymium from waste neodymium magnet. Sep. Purif. Technol. 2018, 192, 62-68. [CrossRef]

32. Padhan, E.; Sarangi, K. Recycling of Nd and Pr from NdFeB magnet leachates with bi-functional ionic liquids based on Aliquat 336 and Cyanex 272. Hydrometallurgy 2017, 167, 134-140. [CrossRef]

33. Padhan, E.; Nayak, A.K.; Sarangi, K. Recovery of neodymium and dysprosium from NdFeB magnet swarf. Hydrometallurgy 2017, 174, 210-215. [CrossRef]

34. Riaño, S.; Binnemans, K. Extraction and separation of neodymium and dysprosium from used $\mathrm{NdFeB}$ magnets: An application of ionic liquids in solvent extraction towards the recycling of magnets. Green Chem. 2015, 17, 2931-2942. [CrossRef]

35. Kim, D.; Powell, L.; Delmau, L.H.; Peterson, E.S.; Herchenroeder, J.; Bhave, R.R. Selective extraction of rare earth elements from permanent magnet scraps with membrane solvent extraction. Environ. Sci. Technol. 2015, 49, 9452-9459. [CrossRef] [PubMed]

36. Dupont, D.; Binnemans, K. Recycling of rare earths from NdFeB magnets using a combined leaching/extraction system based on the acidity and thermomorphism of the ionic liquid [Hbet][Tf $\left.{ }_{2} \mathrm{~N}\right]$. Green Chem. 2015, 17, 2150-2163. [CrossRef] 
37. Lai, W.; Liu, M.; Li, C.; Suo, H.L.; Yue, M. Recycling of a composite powder from NdFeB slurry by co-precipitation. Hydrometallurgy 2014, 150, 27-33. [CrossRef]

38. Binnemans, K.; Jones, P.T.; Blanpain, B.; Van Gerven, T.; Yang, Y.; Walton, A.; Buchert, M. Recycling of rare earths: A critical review. J. Clean. Prod. 2013, 51, 1-22. [CrossRef]

39. USGS (2010-2016) Minerals Yearbook, Rare Earths. Available online: http://minerals.usgs.gov/minerals/ pubs/commodity/rare_earths/index.html\#myb (accessed on 29 May 2020).

40. Alonso, E.; Sherman, A.M.; Wallington, T.J.; Everson, M.P.; Field, R.; Roth, R.; Kirchain, R.E. Evaluating rare earth element availability: A case with revolutionary demand from clean technologies. Environ. Sci. Technol. 2012, 46, 3406-3414. [CrossRef] [PubMed]

41. Schulze, R.; Buchert, M. Estimates of global REE recycling potentials from NdFeB magnet material. Resour. Conserv. Recy. 2016, 113, 12-27. [CrossRef]

42. Du, X.; Graedel, T.E. Global rare earth in-use stocks in NdFeB permanent magnets. J. Ind. Ecol. 2011, 15, 836-843. [CrossRef]

43. Guyonnet, D.; Planchon, M.; Rollat, A.; Escalon, V.; Tuduri, J.; Charles, N.; Vaxelaire, S.; Dubois, D.; Fargier, H. Material flow analysis applied to rare earth elements in Europe. J. Clean. Prod. 2015, 107, 215-228. [CrossRef]

44. Schüler, D.; Buchert, M.; Liu, R.; Dittrich, S.; Merz, C. Study on Rare Earths and Their Recycling (Öko-Institut eV, Darmstadt); The Greens/EFA Group in the European Parliament: Brussels, Belgium, 2011.

45. Rademaker, J.H.; Kleijn, R.; Yang, Y. Recycling as a strategy against rare earth element criticality: A systemic evaluation of the potential yield of NdFeB magnet recycling. Environ. Sci. Technol. 2013, 47, 10129-10136. [CrossRef]

46. Seo, Y.; Morimoto, S. Comparison of dysprosium security strategies in Japan for 2010-2030. Resour. Policy 2014, 39, 15-20. [CrossRef]

47. Gutfleisch, O.; Willard, M.A.; Bruck, E.; Chen, C.; Sankar, S.G.; Liu, J. Magnetic materials and devices for the 21st century: Stronger, lighter, and more energy efficient. Adv. Mater. 2011, 23, 821-842. [CrossRef] [PubMed]

48. Critical Materials Strategy; U.S. Department of Energy, Advanced Research Projects Agency-Energy: Washington, DC, USA, 2010.

49. Brown, D.; Ma, B.; Chen, Z. Developments in the processing and properties of NdFeb-type permanent magnets. J. Magn. Magn. Mater. 2002, 248, 432-440. [CrossRef]

50. Zhou, S.; Dong, Q.; Gao, X. Sintered NdFeB Rare Earth Permanent Magnetic Materials and Technology; Metallurgical Industry Press: Beijing, China, 2011.

51. Önal, M.A.R.; Borra, C.R.; Guo, M.X.; Blanpain, B.; Gerven, T.V. Hydrometallurgical recycling of NdFeB magnets: Complete leaching, iron removal and electrolysis. J. Rare Earth. 2017, 35, 574-584. [CrossRef]

52. Gergoric, M.; Ekberg, C.; Foreman, M.R.S.J.; Steenari, B.-M.; Retegan, T. Characterization and leaching of neodymium magnet waste and solvent extraction of the rare-earth elements using TODGA. J. Sustain. Metall. 2017, 3, 638-645. [CrossRef]

53. Itakura, T.; Sasai, R.; Itoh, H. Resource recycling from Nd-Fe-B sintered magnet by hydrothermal treatment. J. Alloy. Compd. 2006, 408-412, 1382-1385. [CrossRef]

54. Chae, H.J.; Kim, Y.D.; Kim, B.S.; Kim, J.G.; Kim, T.S. Experimental investigation of diffusion behavior between molten Mg and Nd-Fe-B magnets. J. Alloy. Compd. 2014, 586, S143-S149. [CrossRef]

55. Önal, M.A.R.; Aktan, E.; Borra, C.R.; Blanpain, B.; Gerven, T.V.; Guo, M.X. Recycling of NdFeB magnets using nitration, calcination and water leaching for REE recycling. Hydrometallurgy 2017, 167, 115-123. [CrossRef]

56. Hoogerstraete, T.V.; Blanpain, B.; Gerven, T.V.; Binnemans, K. From NdFeB magnets towards the rare-earth oxides: A recycling process consuming only oxalic acid. RSC Adv. 2014, 4, 64099-64111. [CrossRef]

57. Herbst, J.F.; Croat, J.J.; Pinkerton, F.E. Relationships between crystal structure and magnetic properties in $\mathrm{Nd}_{2} \mathrm{Fe}_{14}$ B. Phys. Rev. B 1984, 29, 4176. [CrossRef]

58. Chung, K.W.; Kim, C.J.; Yoon, H.S. Novel extraction process of rare earth elements from NdFeB powders via alkaline treatment. Arch. Metall. Mater. 2015, 60, 1301-1305. [CrossRef]

59. Khlopkov, K.; Gutfleisch, O.; Eckert, D.; Hinz, D.; Wallb, B.; Rodewald, W.; Müller, K.-H.; Schultz, L. Local texture in Nd-Fe-B sintered magnets with maximised energy density. J. Alloy. Compd. 2004, 365, 259-265. [CrossRef]

60. Makarova, I.; Soboleva, E.; Osipenko, M.; Kurilo, I.; Laatikainen, M.; Repo, E. Electrochemical leaching of rare-earth elements from spent $\mathrm{NdFeB}$ magnets. Hydrometallurgy 2020, 192, 105264. [CrossRef] 
61. Önal, M.A.R.; Borra, C.R.; Guo, M.; Blanpain, B.; Gerven, T.V. Recycling of NdFeB magnets using sulfation, selective roasting, and water leaching. J. Sustain. Metall. 2015, 1, 199-215. [CrossRef]

62. Jha, M.K.; Kumari, A.; Panda, R.; Kumar, J.R.; Yoo, K.; Lee, J.Y. Review on hydrometallurgical recovery of rare earth metals. Hydrometallurgical 2016, 165, 2-26. [CrossRef]

63. Jyothi, R.K.; Thenepalli, T.; Ahn, J.W.; Parhi, P.K.; Chung, K.W.; Lee, J.-Y. Review of rare earth elements recovery from secondary resources for clean energy technologies: Grand opportunities to create wealth from waste by saving energy. J. Clean. Prod. 2020, 267, 122048. [CrossRef]

64. Kumari, A.; Panda, R.; Jha, M.K.; Kumar, J.R.; Lee, J.Y. Process development to recover rare earth metals from monazite mineral: A review. Miner. Eng. 2015, 79, 102-115. [CrossRef]

65. Lee, J.C.; Kim, W.B.; Jeong, J.; Yoon, I.J. Extraction of neodymium from Nd-Fe-B magnet scraps by sulfuric Acid. J. Korean Inst. Met. Mater. 1998, 36, 967.

66. Niinae, M.; Yamaugchi, K.; Nakahiro, Y. Study on recycling of rare earth magnet scrap. J. Mining Mater. Pro. Ins. 1994, 110, 337.

67. Koyama, K.; Kitajima, A.; Tanaka, M. Selective leaching of rare-earth elements from an Nd-Fe-B magnet. Kidorui (Rare Earths) 2009, 54, 36-37.

68. Koyama, K.; Tanaka, M. The Latest Technology Trend and Resource Strategy of Rare Earths; Machida, K., Ed.; CMC Press: Tokyo, Japan, 2011; pp. 127-131.

69. Kumari, A.; Sinha, M.K.; Pramanik, S.; Sahu, S.K. Recovery of rare earths from spent NdFeB magnets of wind turbine: Leaching and kinetic aspects. Waste Manag. 2018, 75, 486-498. [CrossRef]

70. Hoogerstraete, T.V.; Wellens, S.; Verachtert, K.; Binnemans, K. Removal of transition metals from rare earths by solvent extraction with an undiluted phosphonium ionic liquid: Separations relevant to rare-earth magnet recycling. Green Chem. 2013, 15, 919-927. [CrossRef]

71. Hoogerstraete, T.V.; Binnemans, K. Highly efficient separation of rare earths from nickel and cobalt by solvent extraction with the ionic liquid trihexyl (tetradecyl) phosphonium nitrate: A process relevant to the recycling of rare earths from permanent magnets and nickel metal hydride batteries. Green Chem. 2014, 16, 1594-1606.

72. Martina, O.; Amy, V.B.; Bart, B.; Koen, B. Selective roasting of Nd-Fe-B permanent magnets as a pretreatment step for intensifed leaching with an ionic liquid. J. Sustain. Metall. 2020, 6, 91-102.

73. Rabatho, J.P.; Tongamp, W.; Takasaki, Y.; Haga, K.; Shibayama, A. Recycling of Nd and Dy from rare earth magnetic waste sludge by hydrometallurgical process. J. Mater. Cycles Waste 2012, 15, 171-178. [CrossRef]

74. Kataoka, Y.; Ono, T.; Tsubota, M.; Kitagawa, J. Improved room-temperature-selectivity between $\mathrm{Nd}$ and Fe in $\mathrm{Nd}$ recovery from Nd-Fe-B magnet. AIP Adv. 2015, 5, 117212. [CrossRef]

75. Yoon, H.S.; Kim, C.J.; Chung, K.W.; Jeon, S.; Park, I.; Yoo, K.; Jha, M.K. The effect of grinding and roasting conditions on the selective leaching of Nd and Dy from NdFeB magnet scraps. Metals 2015, 5, 1306-1314. [CrossRef]

76. Xie, F.; Zhang, T.A.; Dreisinger, D.; Doyle, F. A critical review on solvent extraction of rare earths from aqueous solutions. Miner. Eng. 2014, 56, 10-28. [CrossRef]

77. Venkatesan, P.; Vander Hoogerstraete, T.; Hennebel, T.; Binnemans, K.; Sietsma, J.; Yang, Y. Selective electrochemical extraction of REEs from NdFeB magnet waste at room temperature. Green Chem. 2018, 20, 1065-1073. [CrossRef]

78. Venkatesan, P.; Sun, Z.H.I.; Sietsma, J.; Yang, Y. An environmentally friendly electro-oxidative approach to recover valuable elements from NdFeB magnet waste. Sep. Purif. Technol. 2018, 191, 384-391. [CrossRef]

79. Venkatesan, P.; Vander Hoogerstraete, T.; Binnemans, K.; Sun, Z.; Sietsma, J.; Yang, Y. Selective extraction of rare-earth elements from $\mathrm{NdFeB}$ magnets by a room-temperature electrolysis pretreatment step. ACS Sustain. Chem. Eng. 2018, 6, 9375-9382. [CrossRef]

80. Yoon, H.-S.; Kim, C.-J.; Chung, K.W.; Kim, S.-D.; Kumar, J.R. Process development for recovery of dysprosium from permanent magnet scraps leach liquor by hydrometallurgical techniques. Can. Metall. Q. 2015, 54, 318-327. [CrossRef]

81. Yoon, H.-S.; Kim, C.-J.; Chung, K.W.; Kim, S.-D.; Kumar, J.R. Recovery process development for the rare earths from permanent magnets scraps leach liquors. J. Brazil. Chem. Soc. 2015, 26, 1143-1151. [CrossRef]

82. Lyman, J.W.; Palmer, G.R. Recycling of rare earths and iron from NdFeB magnet scrap. High Temp. Mater. Proc. 1993, 11, 175-187.

83. Lee, C.-H.; Chen, Y.J.; Liao, C.H.; Popuri, S.R.; TSAI, S.L.; Hung, C.E. Selective leaching process for neodymium recycling from scrap Nd-Fe-B magnet. Metall. Mater. Trans. A 2013, 44, 5825-5833. [CrossRef] 
84. Itakura, T.; Sasai, R.; Itoh, H. A novel recovery method for treating wastewater containing fluoride and fluoroboric acid. Bull. Chem. Soc. Jpn. 2006, 79, 1303-1307. [CrossRef]

85. Itakura, T.; Sasai, R.; Itoh, H. In situ solid/liquid separation effect for high-yield recycling of boron and fluorine from aqueous media containing borate or fluoroborate ions. Bull. Chem. Soc. Jpn. 2007, 80, 2014-2018. [CrossRef]

86. Auerbach, R.; Bokelmann, K.; Stauber, R.; Gutfleisch, O.; Schnell, S.; Ratering, S. Recycling of rare earth metals out of end of life magnets by bioleaching with various bacteria as an example of an intelligent recycling strategy. Miner. Eng. 2019, 134, 104-117. [CrossRef]

87. Yoon, H.S.; Kim, C.J.; Lee, J.Y.; Kim, S.D.; Lee, J.C. Separation of neodymium from NdFeB permanent magnet scrap. J. Korean Inst. Resour. Recycl. 2003, 12, 57-63.

88. Yoon, H.-S.; Kim, C.-J.; Chung, K.-W.; Kim, S.-D.; Lee, J.-Y.; Kumar, J.R. Solvent extraction, separation and recovery of the dysprosium $(\mathrm{Dy})$ and neodymium $(\mathrm{Nd})$ from aqueous solutions: Waste recycling strategies for permanent magnet processing. Hydrometallurgy 2016, 165, 27-43. [CrossRef]

89. Reddy, B.R.; Kumar, J.R. Rare earths extraction, separation and recovery from phosphoric acid media. Solvent Extr. Ion Exc. 2016, 34, 226-240. [CrossRef]

90. Gergoric, M.; Ravaux, C.; Steenari, B.-M.; Espegren, F.; Retegan, T. Leaching and Recovery of Rare-Earth Elements from Neodymium Magnet Waste Using Organic Acids. Metals 2018, 8, 721. [CrossRef]

91. Lee, J.Y.; Jha, A.K.; Kumari, A.; Kumar, J.R.; Jha, M.K.; Kumar, V. Neodymium recovery by precipitation from synthetic leach liquor of concentrated rare earth mineral. J. Metall. Mater. Sci. 2011, 53, 349-354.

92. Sasai, R.; Shimamura, N. Technique for recovering rare-earth metals from spent sintered Nd-Fe-B magnets without external heating. J. Asian Ceram. Soc. 2018, 4, 155-158. [CrossRef]

93. Kikuchi, Y.; Matsumiya, M.; Kawakami, S. Extraction of rare earth ions from Nd-Fe-B magnet wastes with TBP in Tricaprylmethylammonium nitrate. Solvent Extr. Dev. 2014, 21, 137-145. [CrossRef]

94. Saito, T.; Sato, H.; Motegi, T. Recovery of rare earths from sludges containing rare-earth elements. J. Alloy. Compd. 2006, 425, 145-147. [CrossRef]

95. Cai, J.; Dai, J.; Zhou, X. Thermodynamic analysis on preparation of zinc doped $\mathrm{Co}_{2}-\mathrm{Y}$ planar hexagonal ferrite powder by chemical co-precipitation method. Chin. J. Inorg. Chem. 2008, 24, 1943-1948.

96. Su, J.; Su, Y.; Lai, Z. Thermodynamic analysis of preparation of multiple carbonate of Ni, Co and Mn by co-precipitation method. J. Chin. Ceram. Soc. 2006, 34, 695-698.

97. Kołodyńska, D.; Hubicki, Z. Investigation of sorption and separation of lanthanides on the ion exchangers of various types. In Ion Exchange Technologies; Kilislioglu, A., Ed.; InTech: London, UK, 2012; ISBN 978-953-51-0836-8.

98. Huang, L.H. Chemical Beneficiation; Metallurgical Industry Press: Beijing, China, 2012.

99. Deshpande, S.M.; Mishra, S.L.; Gajankush, R.B.; Thakur, N.V.; Koppiker, K.S. Recovery of high purity $\mathrm{Y}_{2} \mathrm{O}_{3}$ by solvent extraction route using organo-phosphorus extractants. Miner. Process. Extr. Metall. Rev. Int. J. 1992, 10, 267-273. [CrossRef]

100. Yin, S.; Wu, W.; Zhang, B.; Zhang, F.; Luo, Y.; Li, S.; Bian, X. Study on separation technology of Pr and Nd in D2EHPA-HCl-LA coordination extraction system. J. Rare Earths 2012, 28, 111-115. [CrossRef]

101. Lee, M.-S.; Lee, J.Y.; Kim, J.S.; Lee, G.S. Solvent extraction of neodymium ions from hydrochloric acid solution using PC88A and saponified PC88A. Sep. Purif. Technol. 2005, 46, 72-78. [CrossRef]

102. El-Kot, A.M. Solvent extraction of neodymium, europium and thulium by di-(2-ethylhexyl) phosphoric acid. J. Radioanal. Nucl. Chem. 1993, 170, 207-214. [CrossRef]

103. Onoda, H.; Nakamura, R. Recycling of neodymium from an iron-neodymium solution using phosphoric acid. J. Environ. Chem. Eng. 2014, 2, 1186-1190. [CrossRef]

104. Preston, J.S.; Preez, A.C. The separation of europium from a middle rare earth concentrate by combined chemical reduction, precipitation and solvent-extraction methods. J. Chem. Technol. Biot. 1996, 65, 93-101. [CrossRef]

105. Maharana, L.N.; Nair, V.R. Production of value added rare earths from monazite by solvent extraction. In Light Metals; Kvande, H., Ed.; TMS 2005: Warrendale, PA, USA, 2005; pp. 1163-1166.

106. Mohammadi, M.; Forsberg, K.; Kloo, L.; Cruz, J.M.D.L.; Rasmuson, A. Separation of ND(III), DY(III) and Y(III) by solvent extraction using D2EHPA and EHEHPA. Hydrometallurgy 2015, 156, 215-224. [CrossRef] 
107. Sarangi, K.; Reddy, B.R.; Das, R.P. Extraction studies of cobalt(II) and nickel(II) from chloride solutions using Na-Cyanex 272: Separation of Co(II)/Ni(II) by the sodium salts of D2EHPA, PC88A and Cyanex 272 and their mixtures. Hydrometallurgy 1999, 52, 253-265. [CrossRef]

108. Thakur, N.V.; Jayawant, D.V.; Iyer, N.S.; Koppiker, K.S. Separation of neodymium from lighter rare earths using alkyl phosphonic acid, PC88A. Hydrometallurgy 1993, 34, 99-108. [CrossRef]

109. Devi, N.B.; Nathsarma, K.C.; Chakravortty, V. Separation and recycling of cobalt(II) and nickel(II) from sulphate solutions using sodium salts of D2EHPA, PC88A and Cyanex 272. Hydrometallurgy 1999, 49, 47-61. [CrossRef]

110. Devi, N.B.; Nathsarma, K.C.; Chakravortty, V. Separation of divalent manganese and cobalt ions from sulphate solutions using sodium salts of D2EHPA, PC88A and Cyanex 272. Hydrometallurgy 2000, 54, 117-131. [CrossRef]

111. Padhan, E.; Sarangi, K. Solvent extraction of Nd using organo-phosphorus extractants from chloride media. Chem. Technol. Biotechnol. 2015, 90, 1869-1875. [CrossRef]

112. Pavóna, S.; Fortunya, A.; Collb, M.T.; Sastrec, A.M. Neodymium recovery from NdFeB magnet wastes using Primene 81R.Cyanex 572 IL by solvent extraction. J. Environ. Manag. 2018, 222, 359-367. [CrossRef] [PubMed]

113. Rice, A.C.; Stone, C.A. Amines in Liquid-Liquid Extraction of Rare Earth Elements; US Department of the Interior, Bureau of Mines: Washington, DC, USA, 1961; p. 5923.

114. Hsu, K.H.; Huang, C.H.; King, T.C.; Li, P.K. Separation of praseodymium and neodymium in high purity $(99.9 \%)$ by counter-current exchange extraction and its mechanism. In Proceedings of the International Solvent Extraction Conference'80 (ISEC'80), Liege, Belgium, 6-12 September 1980; Society of Chemical Industry: London, UK; Volume 2, pp. 80-82.

115. El-Yamani, I.S.; Shabana, E.L. Solvent extraction of lanthanum(III) from sulfuric acid solutions by Primene JMT. J. Less-Common Metals 1985, 105, 255-261. [CrossRef]

116. Huang, C.H.; Jin, T.Z.; Li, B.G.; Li, J.R.; Xu, G.X. Studies on extraction mechanism of the rare earths with quaternary ammonium salts. In Proceedings of the International Solvent Extraction Conference-ISEC'86; Dechema: Frankfurt, Germany, 1986; pp. 215-221.

117. Cerna, M.; Volaufova, E.; Rod, V. Extraction of light rare earth elements by amines at high inorganic nitrate concentration. Hydrometallurgy 1992, 28, 339-352. [CrossRef]

118. Lu, D.; Horing, J.S.; HOH, Y.C. The separation of neodymium by quaternary amine form didymium nitrate solution. J. Less-Common Metals 1989, 149, 219-224. [CrossRef]

119. Preston, J.S. The recycling of rare earth oxides from a phosphoric acid byproduct, Part 4: The preparation of magnet-grade neodymium oxide from the light rare earth fraction. Hydrometallurgy 1996, 42, 151-167. [CrossRef]

120. Mincher, B. Radiation chemistry in the reprocessing and recycling of spent nuclear fuels. In Reprocessing and Recycling of Spent Nuclear Fuel; Taylor, R., Ed.; Elsevier: Cambridge, UK, 2015; pp. 191-213.

121. Tachimori, S.; Sasaki, Y.; Suzuki, S. Modification of TODGA-n-dodecane solvent with a monoamide for high loading of lanthanides(III) and actinides(III). Solvent Extr. Ion. Exch. 2002, 20, 687-699. [CrossRef]

122. Marcus, Y. Principles of Solubility and Solutions. In Solvent Extraction Principles and Practise, 2nd ed.; Rydberg, J., Cox, M., Musicas, C., Choppin, G.R., Eds.; Marcel Dekker: New York, NY, USA, 2004; pp. $27-81$.

123. Kim, D. A supported liquid membrane system for the selective recycling of rare earth elements from neodymium-based permanent magnets. Sep. Sci. Technol. 2017, 51, 1716-1726. [CrossRef]

124. Wang, X.; Li, W.; Meng, S.; Li, D. The extraction of rare earths using mixtures of acidic phosphorus based reagents or their thio-analogues. J. Chem. Technol. Biot. 2006, 81, 761-766. [CrossRef]

125. Santhi, P.B.; Reddy, M.L.P.; Ramamohan, T.R.; Damodaran, A.D. Liquid-liquid extraction of yttrium (III) with mixtures of organophosphorous extractants: Theoretical analysis of extraction behavior. Hydrometallurgy 1991, 27, 169-177. [CrossRef]

126. Tian, M.; Song, N.; Wang, D.; Quan, X.; Jia, Q.; Liao, W.; Lin, L. Applications of the binary mixture of sec-octylphenoxyacetic acid and 8-hydroxyquinoline to the extraction of rare earth elements. Hydrometallurgy 2012, 111-112, 109-113. [CrossRef]

127. Tian, M.; Jia, Q.; Liao, W. Studies on synergistic solvent extraction of rare earth elements from nitrate medium by mixtures of 8-hydroxyquinoline with Cyanex 301 or Cyanex 302. J. Rare Earth. 2013, 31, 604-608. [CrossRef] 
128. Huang, X.; Li, J.; Zhang, Y.; Long, Z.; Wang, C.; Xue, X. Synergistic extraction of $\mathrm{Nd}^{3+}$ and $\mathrm{Sm}^{3+}$ with the mixtures of P204 and P507 in acidic sulfate solutions. Chin. J. Nonferrous Met. 2008, 18, 366-371.

129. Luo, X.; Huang, X.; Zhu, Z.; Long, Z.; Liu, Y. Synergistic extraction of cerium from sulfuric acid medium using mixture of 2-ethylhexyl phosphonic acid mono 2-ethylhexyl ester and Di-(2-ethyl hexyl) phosphoric acid as extractant. J. Rare Earth. 2009, 27, 119-122. [CrossRef]

130. Baes, C.F.J. The extraction of metallic species by dialkylphosphoric acids. J. Inorg. Nucl. Chem. 1962, 24, 707-720. [CrossRef]

131. Sato, T. Liquid-liquid extraction of rare-earth elements from aqueous acid solutions by acid organophosphorous compounds. Hydrometallurgy 1989, 22, 121-140. [CrossRef]

132. Zhang, C.; Wang, L.; Huang, X.; Dong, D.; Long, Z.; Zhang, Y. Yttrium extraction from chloride solution with a synergistic system of 2-ethylhexyl phosphonic acid mono-(2-ethylhexyl) ester and bis (2, 4, 4-trimethylpentyl) phosphinic acid. Hydrometallurgy 2014, 147-148, 7-12. [CrossRef]

133. Zhang, F.; Wu, W.; Bian, X.; Zeng, W. Synergistic extraction and separation of lanthanum (III) and cerium (III) using a mixture of 2-ethylhexylphosphonic mono-2-ethylhexyl ester and di-2-ethylhexyl phosphoric acid in the presence of two complexing agents containing lactic acid and citric acid. Hydrometallurgy 2014, 149, 238-243. [CrossRef]

134. Panda, N.; Devi, N.B.; Mishra, S. Extraction of neodymium(III) using binary mixture of Cyanex 272 and Cyanex 921/Cyanex 923 in kerosene. J. Radioanal. Nucl. Chem. 2013, 296, 1205-1211. [CrossRef]

135. Liu, Y.; Jeon, H.S.; Lee, M.S. Solvent extraction of Pr and Nd from chloride solution by the mixtures of Cyanex 272 and amine extractants. Hydrometallurgy 2014, 150, 61-67. [CrossRef]

136. Kumar, B.N.; Reddy, B.R.; Kantam, M.L.; Kumar, J.R.; Lee, J.Y. Synergistic solvent extraction of neodymium(iii) from chloride solutions using a mixture of triisooctylamine and bis(2,4,4-Trimethylpentyl) monothiophosphinic acid. Sep. Sci. Technol. 2014, 49, 130-136. [CrossRef]

137. El-Nadi, Y.A. Lanthanum and neodymium from Egyptian monazite: Synergistic extractive separation using organophosphorus reagents. Hydrometallurgy 2012, 119-120, 23-29. [CrossRef]

138. Huddleston, J.G.; Willauer, H.D.; Swatloski, R.P.; Visser, A.E.; Rogers, R.D. Room temperature ionic liquids as novel media for 'clean' liquid-liquid extraction. Chem. Commun. 1998, 16, 1765-1766. [CrossRef]

139. Nakashima, F.; Maruyama, T.; Goto, M. Feasibility of ionic liquids as alternative separation media for industrial solvent extraction processes. Ind. Eng. Chem. Res. 2005, 44, 4368-4372. [CrossRef]

140. Billard, I.; Ouadi, A.; Gaillard, C. Liquid-liquid extraction of actinides, lanthanides, and fission products by use of ionic liquids: From discovery to understanding. Anal. Bioanal. Chem. 2011, 400, 1555-1566. [CrossRef]

141. Wei, G.; Yang, Z.; Chen, C. Room temperature ionic liquid as a novel medium for liquid/liquid extraction of metal ions. Anal. Chim. Acta 2003, 488, 183-192. [CrossRef]

142. Zuo, Y.; Liu, Y.; Chen, J.; Li, D.Q. The separation of cerium(IV) from nitric acid solutions containing thorium(IV) and lanthanides(III) using pure $\left[\mathrm{C}_{8}\right.$ mim $] \mathrm{PF}_{6}$ as extracting phase. Ind. Eng. Chem. Res. 2008, 47, 2349-2355. [CrossRef]

143. Wang, K. Recovery of rare earth elements with ionic liquids. Green Chem. 2017, 19, 4469-4493. [CrossRef]

144. Rout, A.; Binnemans, K. Influence of the ionic liquid cation on the solvent extraction of trivalent rare-earth ions by mixtures of Cyanex 923 and ionic liquids. Dalton Trans. 2015, 44, 1379-1387. [CrossRef]

145. Jensen, M.P.; Neuefeind, J.; Beitz, J.V.; Skanthakumar, S.; Soderholm, L. Mechanisms of metal ion transfer into room-temperature ionic liquids: The role of anion exchange. J. Am. Chem. Soc. 2003, 125, 15466-15473. [CrossRef]

146. Fukikoa, K.; Yousuke, S.; Yuzo, B.; Yusuke, K.; Kojiro, S.; Noiho, K.; Masahiro, G. Application of ionic liquids to extraction separation of rare earth metals with an effective diglycol amic acid extractant. J. Chem. Eng. Jpn. 2011, 44, 307-312.

147. Yang, H.; Wang, W.; Cui, H.; Chen, J. Extraction mechanism of rare earths with bifuncional ionic liquids (Bif-ILs) [A336][CA-12]/[A336][CA-100] in nitrate medium. Chin. J. Anal. Chem. 2011, 39, 1561-1566. [CrossRef]

148. Rout, A.; Kotlarska, J.; Dehaen, W.; Binnemans, K. Liquid-liquid extraction of neodymium(III) by dialkylphosphate ionic liquids from acidic medium: The importance of the ionic liquid cation. Phys. Chem. Chem. Phys. 2013, 15, 16533-16541. [CrossRef]

149. Qi, G.; Hino, M.; Yazawa, A. Experimental study on the reduction-diffusion process to produce Fe-Nd, Fe-Sm, Co-Nd and Co-Sm alloys. Mater. Trans. JIM 1990, 31, 463-470. [CrossRef] 
150. Liu, Y.; Chen, J.; Li, D. Application and perspective of ionic liquids on rare earths green separation. Sep. Sci. Technol. 2012, 47, 223-232. [CrossRef]

151. Rout, A.; Binnemans, K. Solvent extraction of neodymium(III) by functionalized ionic liquid trioctylmethylammonium dioctyl diglycolamate in fluorine-free ionic liquid diluent. Ind. Eng. Chem. Res. 2014, 53, 6500-6508. [CrossRef]

152. Wang, W.; Yang, H.; Cui, H.; Zhang, D.; Liu, Y.; Chen, J. Application of bifunctional ionic liquid extractants [A336][CA-12] and [A336][CA-100] to the lanthanum extraction and separation from rare earths in the chloride medium. Ind. Eng. Chem. Res. 2011, 50, 7534-7541. [CrossRef]

153. Rout, A.; Karmakar, S.; Venkatesan, K.A.; Srinivasan, T.G.; Vasudeva, P.R. Room temperature ionic liquid diluent for the mutual separation of europium(III) from americium(III). Sep. Purif. Technol. 2011, 81, 109-115. [CrossRef]

154. Sun, X.; Ji, Y.; Hu, F.; He, B.; Chen, J.; Li, D. The inner synergistic effect of bifunctional ionic liquid extractant for solvent extraction. Talanta 2010, 81, 1877-1883. [CrossRef] [PubMed]

155. Sun, X.; Waters, K.E. The adjustable synergistic effects between acid-base coupling bifunctional ionic liquid extractants for rare earth separation. AICHE J. 2014, 60, 3859-3868. [CrossRef]

(C) 2020 by the authors. Licensee MDPI, Basel, Switzerland. This article is an open access article distributed under the terms and conditions of the Creative Commons Attribution (CC BY) license (http://creativecommons.org/licenses/by/4.0/). 